Review

\title{
Guidelines to Study the Adsorption of Pesticides onto Clay Minerals Aiming at a Straightforward Evaluation of Their Removal Performance
}

\author{
Jorge Cesar Masini ${ }^{1, *(D)}$ and Gilberto Abate ${ }^{2}$ \\ 1 Department of Fundamental Chemistry, Institute of Chemistry, University of São Paulo, \\ Av. Prof. Lineu Prestes 748, São Paulo 05508-000, SP, Brazil \\ 2 Department of Chemistry, Federal University of Paraná, Polytechnique Center, Curitiba 81531-980, PR, Brazil; \\ gilbertoabate@ufpr.br \\ * Correspondence: jcmasini@iq.usp.br
}

Citation: Masini, J.C.; Abate, G. Guidelines to Study the Adsorption of Pesticides onto Clay Minerals Aiming at a Straightforward Evaluation of Their Removal Performance. Minerals 2021, 11, 1282. https://doi.org/10.3390/min11111282

Academic Editor: Yunfei Xi

Received: 14 October 2021

Accepted: 15 November 2021

Published: 18 November 2021

Publisher's Note: MDPI stays neutral with regard to jurisdictional claims in published maps and institutional affiliations.

Copyright: (c) 2021 by the authors. Licensee MDPI, Basel, Switzerland. This article is an open access article distributed under the terms and conditions of the Creative Commons Attribution (CC BY) license (https:// creativecommons.org/licenses/by/ $4.0 /)$.
Abstract: Natural and modified clay minerals have been extensively used for the adsorption/desorption of organic substances, especially pesticides, from waters and wastewater, aiming at pollution control and more efficient use of the herbicides through controlled release. While natural clay minerals efficiently remove organic cations such as paraquat and diquat, the adsorption of anionic or neutral species demands surface chemical modification with, for instance, quaternary ammonium salts containing long alkyl chains. Basic pesticides, on the other hand, are better absorbed in clay minerals modified with polycations. Kinetic studies and adsorption/desorption isotherms provide the parameters needed to evaluate the clay mineral's adsorptive performance towards the pollutant target. However, the direct comparison of these parameters is complicated because the experimental conditions, the analytical techniques, the kinetic and isotherm models, and the numerical fitting method differ among the various studies. The free-energy-related Langmuir constant depends on the degree of site occupation; that is, it depends on the concentration window used to construct the adsorption isotherm and, consequently, on the analytical technique used to quantify the free concentrations. This paper reviews pesticides' adsorption on natural and modified clay minerals and proposes guidelines for designing batch adsorption/desorption studies to obtain easily comparable and meaningful adsorption parameters. Articles should clearly describe the experimental conditions such as temperature, contact time, total concentration window, the solution to adsorbent ratio, the analytical technique, and its detection and quantification limits, besides the fitting models. Research should also evaluate the competitive effects of humic substances, colloidal inorganic particles, and ionic strength to emulate real-world adsorption experiments.

Keywords: montmorillonite; vermiculite; bentonite; organoclays; pesticides; modified clay minerals

\section{Introduction}

The so-called Green Revolution dramatically increased agricultural productivity from the middle of the twentieth century to the present [1]. However, this increase relied heavily on chemical fertilizers and a wide range of pesticides, especially herbicides. Consequently, herbicides' contamination of soils, groundwater, and surface water is a concern of prime importance due to the severe effects of these compounds on humans, animals, and the ecosystem's equilibrium [2-6].

Adsorption is among the most efficient technologies to prevent or remediate pollution from pesticides because it relies on low-cost materials such as biomaterials, aluminum, and iron oxides, or oxyhydroxides, zeolites, and clay minerals. Clay minerals exhibit properties such as high superficial area, high adsorption capacity, low cost, and ready availability that are valuable to the development of herbicide formulations with controlled releasing of active components [7,8], cleanup of contaminated soils, groundwater protection [9], and water treatment [10-12]. 
Clay minerals have gained interest because they are abundant in nature and are environmentally compatible. Montmorillonite $(\mathrm{Mt})$, like other smectites, and vermiculite $(\mathrm{Vt})$, have permanent negative charges generated by the isomorphic substitutions of $\mathrm{Si}^{4+}$ by $\mathrm{Al}^{3+}$ in the tetrahedral sheets and of $\mathrm{Al}^{3+}$ by $\mathrm{Mg}^{2+}$ in the octahedrons. Cations such as $\mathrm{Na}^{+}, \mathrm{Ca}^{2+}$, and $\mathrm{Mg}^{2+}$ in the interlayer keep the electroneutrality. These permanent negative charges interact with cationic herbicides such as paraquat and diquat [13]. Additionally, these interlayer cations are easily exchangeable, for instance, with organic quaternary ammonium salts to produce hydrophobic organoclays suitable for retaining neutral pesticides [14]. Aluminum, $\mathrm{Fe}^{3+}, \mathrm{Cr}^{3+}, \mathrm{Ti}^{4+}, \mathrm{Zr}^{3+}$ exchange with the interlayer cations and form polynuclear cationic species under hydrolysis, increasing the affinity towards anionic species $[15,16]$. Alternatively, the suspension of polycations can be first prepared and then exchanged with the interlayer cation [2]. The exchange of the interlayer cation by a polynuclear hydroxyl metal cation is a modification process named intercalating. Calcinating the intercalated clay minerals produces oxide pillars between the layers, increasing the basal spacing $d(001)$, the specific surface area, and the microporosity, enhancing their adsorption capacity and affinity towards a wide variety of organic molecules, including the pesticides [2,17-19].

The reactivity of the surface silanol and aluminol groups enables chemical modifications to enhance their affinity towards different pollutants or bind them via hydrogen bonding [20-25].

Excellent reviews recently addressed the interactions between organic compounds and clay minerals, aiming to develop controlled released herbicide formulation and water purification $[7,9,26]$. A straightforward comparison of adsorbent efficiencies towards various compounds is possible only if parameters such a mass to volume ratio, kinetic, adsorption isotherms, and thermodynamic constants derived from adsorption experiments are presented. Rather than a comprehensive review, the present paper highlights how sorption/desorption experiments involving pesticides and clay minerals were undertaken in selected articles, critically evaluating how they fit the guidelines presented in Section 2. The goal is to facilitate the experimental design and provide meaningful data interpretation and comparison of the adsorption performances of different absorbates and adsorbents.

\section{Relevant Experimental Conditions}

\subsection{Solid to Solution Ratio}

The solid to solution ratio depends on the distribution coefficient $\left(K_{d}\right)$, defined as $K_{d}=\frac{q_{e}}{c_{e}}, q_{e}$ being the amount of herbicide adsorbed per unit mass of adsorbent at equilibrium, and $c_{e}$ the equilibrium concentration of the free compound in solution. High values of $K_{d}$ imply low values of $c_{e}$; thus, the detectability and sensitivity of the analytical method for the determination of $c_{e}$ also play a key role in defining the proper solid to solution ratio. In general practice, the OECD (Organization for Economic Cooperation and Development) 106 Guidelines for the Testing of Chemicals [27] for soils recommend some preliminary experiments to define the solid to solution ratio by performing some experiments in which the adsorbed percentage lays above $20 \%$, or preferably $>50 \%$, provided that the concentration of the test substance in the aqueous phase is high enough to be measured accurately.

\subsection{Data Treatment}

Independent of using natural or modified clay minerals, evaluating the adsorption/release rates, adsorption capacity, and adsorption affinity demands a series of kinetic and isothermal adsorption/desorption (equilibrium) experiments.

In a parallel batch approach, the known mass of clay mineral (adsorbent) contained in several test tubes is dispersed in a known volume of a standard pesticide (the adsorbate) under controlled conditions (agitation speed and temperature). After a given contact time (in kinetic studies) or after reaching the adsorption equilibrium (in isothermal and thermodynamic studies), the solution is separated by filtration or centrifugation. The particle-free solution is analyzed to determine the free fraction of the adsorbate. Usually, a mass balance enables the computation of the amount of adsorbed substance. The kinetic 
experiments help define a contact time approaching the equilibrium to be further used in the adsorption/desorption isotherms. The analytical measurements may be strongly affected by the adsorption of the studied compound in the recipient walls. Thus, for molecular and nonpolar substances with the logarithm of the octanol: water partition $\left(\log K_{O W}\right)>4$ borosilicate glass flasks should be used. In contrast, ionic and polar substances $\left(\log K_{O W}<1.5\right)$ should be studied in polymeric flasks such as the polypropylene centrifuge tubes. Blank experiments to correct for adsorption on the recipient walls are strongly recommended [27].

The adsorbed amount of pesticide $(q)$ can be computed as:

$$
q=\frac{\left(c_{i}-c_{t}\right) V}{m}
$$

where $c_{i}$ is the initial concentration of pesticide, $c_{t}$ is the free concentration after a given contact time, $t$, with the adsorbent, $V$ is the volume of solution dispersing the adsorbents, and $m$ is the mass of the adsorbent.

\subsection{Adsorption Kinetics}

Pore filling and intraparticle diffusion of pesticides onto pores of natural and modified clay minerals materials can take several hours to reach the equilibrium, followed by many fast interaction mechanisms (electrostatic attraction/ion exchange, hydrogen bonding, van-der-Waals, $\pi-\pi$ interaction). However, many studies use an arbitrary contact time of $24 \mathrm{~h}$ to construct the adsorption isotherms without providing evidence that adsorption attained or at least approached equilibrium.

On the other hand, if only surface groups are available for interactions, the equilibrium approaches much more quickly. In these cases, as time goes on, the amount of adsorbate per mass of adsorbent $\left(q_{t}\right)$ as a function of the contact time may result in a plot in which $q_{t}$ remains constant, producing a straight line parallel to the $x$-axis (time). Tran et al. demonstrated that using data obtained over a significant time interval after attaining equilibrium, or very close to it, leads to erroneous conclusions regarding adsorption kinetics [28].

Before constructing the adsorption isotherm and determining thermodynamic parameters, the kinetics should be studied in detail, informing experimental parameters such as temperature, mass to volume ratio, initial concentration, speed of agitation, and the method used to separate the supernatant solution (centrifugation, filtration, or both). The graph of $q_{t}$ vs. $t$ should be published in the main text or as supplementary information. However, this review demonstrates that only a few articles investigated the sorption kinetics to design the equilibrium experiments.

Having the data of $q_{t}$ and $t$, the most common approach to investigate the adsorption kinetics is fitting the data to Lagergren's first order, pseudo-second-order, and intraparticle diffusion kinetic models.

\subsection{Pseudo-First Order Model}

The nonlinear Lagergren's first-order equation, or the pseudo-first-order model, appears in Equation (2), whereas Equation (3) shows the most commonly used linearized expression [28,29]:

$$
\begin{gathered}
q_{t}=q_{e}\left(1-\exp ^{-k_{1} t}\right) \\
\ln \left(q_{e}-q_{t}\right)=-k_{1} t+\ln \left(q_{e}\right)
\end{gathered}
$$

In these equations, $q_{t}$ and $q_{e}$ are the amounts of adsorbate adsorbed per unit mass of adsorbent at the contact time $t$ and equilibrium, respectively; $k_{1}$ is the rate constant. Usually, this equation fits the data only during the initial adsorption steps (20-30 $\mathrm{min}$ ) [30]. This short interval imposes some difficulties in producing high precision results due to the need to provide reproducible stirring conditions and reproducible times before the phase separations. However, automated online sampling and tangential filtration produce 
precise results with a high temporal resolution, as demonstrated by the paraquat and fulvic acid adsorption onto vermiculite [13,31].

The linearized form (Equation (3)) requires the knowledge of $q_{e}$, which demands its determination in a separate experiment (at equilibrium) or through a rough approximation of $q_{e}$ as the $q_{t}$ obtained at the longest contact time. Using nonlinear regression with Equation (2) circumvents these problems and enables the simultaneous determination of $k_{1}$ and $q_{e}$ parameters directly from the kinetic data. Most papers still use the linearized equation despite the availability of nonlinear regression subroutines in popular software packages such as OriginLab (any version, OriginLab Corporation, Northampton, MA, USA) and Microsoft Office Excel (any version, Microsoft Corporation, Redmond, WA, USA) using the add-in Solver program [28].

\subsection{Pseudo-Second-Order Model}

The pseudo-second-order rate model appears as Equation (4), where $k_{2}$ is the pseudosecond-order rate constant [32].

$$
q_{t}=\frac{q_{e}^{2} k_{2} t}{q_{e} k_{2} t+1}
$$

One of the linearized forms of Equation (4) is:

$$
\frac{t}{q_{t}}=\left(\frac{1}{q_{e}}\right) t+\frac{1}{k_{2} q_{e}^{2}}
$$

From Equation (5), the slope provides $1 / q_{e}$, and the intercept enables the computation of $k_{2}$. Invariably, linear regression with Equation (5) provides excellent fittings $\left(R^{2}>0.99\right)$, but these results must be carefully evaluated because, in some cases, the excellent fitting by linear regression is not accompanied by the nonlinear fitting. The advantage of nonlinear methods is that the error distribution does not alter as in linear methods [33]. Thus, as discussed for the pseudo-first-order rate equation, the experimental data should be preferably fitted using nonlinear regression.

Fitting the data to the pseudo-second-order model has been attributed to the chemisorption mechanism. However, this statement has been criticized because the $q_{e}$ and $k_{2}$ do not allow one to make such a statement. Tran et al. [28] pointed out that only combining the characterization by multiple analytical techniques and thermodynamic adsorption data (enthalpy and entropy changes, activation energy, adsorption energy) confirm if physical or chemical processes explain the adsorption $[34,35]$.

\subsection{Intraparticle Diffusion}

The intraparticle diffusion model follows Equation (6), described by Weber and Morris in 1963 [36].

$$
q_{t}=k_{i d} t^{0.5}+C
$$

where $k_{i d}$ is the intraparticle diffusion rate constant, and term $C$ (Equation (6)) is related to the thickness of the boundary layer. This model is useful to identify if intra-particle diffusion is the rate-controlling step. Four steps describe the adsorption kinetics on porous sorbents. The first step involves the rapid convective transport of the adsorbate from the bulk solution to the boundary layer consisting of the stagnant solution layer adjacent to the particle. The second step is a slow diffusion step through the boundary layer or film to the adsorption sites located on the external surface of the adsorbent. In porous particles, the third step is the slow diffusional transport of the adsorbate through the stagnant solution filling the pores. This third step is the intraparticle diffusion of adsorbate towards the adsorption sites on the pore wall surface, where the fourth (and fast) step of adsorption occurs.

If a plot of $q_{t}$ as a function of $t^{0.5}$ is linear and passes through the origin, the intraparticle diffusion controls the adsorption rate. If the intraparticle plot gives multiple linear 
regions and the term $C>0$, multistep mechanisms control the adsorption and indicate that adsorption sites are available on the external surface of the adsorbent $[28,36]$.

Since agitation rate and temperatures strongly influence the mass transfer of the adsorbate from the bulk solution to the adsorption sites by convective and diffusional transport, they should be precisely reported and kept constant along with the kinetic experiments.

\subsection{Adsorption Isotherms}

An adsorption isotherm is the plot of $q_{e}$ as a function of the adsorbate equilibrium concentration $\left(c_{\mathrm{e}}\right)$ at a constant temperature after the systems reach equilibrium. The information from adsorption isotherms, typically adsorption capacity and adsorption constants, helps design scaled-up adsorptive systems. Thus, the adsorption isotherms data must be measured after the kinetic studies that determine the contact time and agitation rate (at a given temperature) needed for the measurements at equilibrium.

Other experimental conditions requiring rigorous control and reporting in the adsorption isotherms and kinetics are the $\mathrm{pH}$, ionic strength, and the presence of major divalent metal cations because they influence the zeta potential of clay mineral particles, thus influencing their interaction with the target sorbates, especially the ionic and zwitterionic ones. However, despite the importance of these variables on adsorption efficiency, they are not very often controlled along adsorption isotherm, and in some cases, are not even mentioned [28].

Several adsorption isotherm models were already described, but this review will focus on the two more widely used ones, the Langmuir and Freundlich equations. Equation (7) shows the Langmuir expression.

$$
q=q_{\max } \frac{K_{L} c_{e}}{1+K_{L} c_{e}}
$$

where $q_{\max }$ is the maximum amount of solute adsorbed per unit mass of adsorbent $\left(\mathrm{mg} \mathrm{kg}^{-1}\right.$, or $\mu \mathrm{mol} \mathrm{kg}{ }^{-1}$, for instance), and $K_{L}$ is the Langmuir adsorption constant ( $\mathrm{L} \mathrm{kg}^{-1}$ ) [28]. Despite the easy implementation of nonlinear regression analysis to investigate the fitting of the experimental data to the model and computation of $q_{\max }$ and $K_{L}$, most authors still use one of the four linearized forms of the Langmuir equation [28]. Although the computation of $q_{\max }$ and $K_{L}$ from slope or intercept is straightforward, this transformation introduces error into the independent variable $\left(c_{e}\right)$, altering the weight of each data point on the fitting, thus causing differences between the fitted parameters obtained by nonlinear and linear regression analysis [28,37]. Even using the nonlinear regression fitting, the adsorption data do not fit the standard Langmuir equation in many cases. The main reason for these deviations is that the original assumptions Langmuir made to develop the equations [38] may not describe the experimental data. These assumptions are: (i) there is a fixed number of adsorption sites available on the adsorbent surface and that these sites interact with the adsorbate with the same energy; (ii) the adsorption is reversible, (iii) the adsorption occurs as a monolayer, that is, once the adsorbate occupies one site no further adsorption occurs at that site, and (iv) no interaction occurs between adsorbate species.

Adsorption on clay minerals may occur at the external surface, in the interlayer space, or at a modifier. Assumption (i) may not be adequate to describe the adsorption on these clay minerals. Equation (8) shows the two-site (four parameters) Langmuir equation [37]:

$$
q=q_{\max , 1} \frac{K_{L, 1} c_{e}}{1+K_{L, 1} c_{e}}+q_{\max , 2} \frac{K_{L, 2} c_{e}}{1+K_{L, 2} c_{e}}
$$

where indexes 1 and 2 refer to the two different adsorption sites and the parameters $q_{\max }$ and $K_{L}$ have the same meaning defined in Equation (7). Two-sites Langmuir equation is usually linearized as the Scatchard plot [28], but this strategy suffers from the subjective choices of the linear portions and the inherent linearization errors. Fitting the data to the 
two sites equation is more accessible by nonlinear regression with OriginLab software or exploring the add-in Solver in Microsoft Excel [37].

Another model is the so-called three-parameter Langmuir-Freundlich model (Equation (9)), also known as the exponential Langmuir or one-site Sips isotherm model, which is a power function based on the assumption of a continuous distribution of affinity coefficients [37,39]:

$$
q=q_{\max } \frac{K_{L F} c_{e}^{\beta}}{1+K_{L F} c_{e}^{\beta}}
$$

where the $K_{L F}$ is the adsorption affinity parameter and $\beta$ refers to the Langmuir-Freundlich heterogeneity index.

From the $K_{L}$, it is possible to calculate the dimensionless constant separation factor $\left(R_{L}\right)$ using Equation (10):

$$
R_{L}=\frac{1}{1+K_{L} C_{0}}
$$

where $c_{0}$ is the largest initial concentration of adsorbate used in the adsorption isotherm. If $0<R_{L}<1$, the adsorption is considered favorable, if $R_{L}>1$ the adsorption is unfavorable and if $R_{L}=0$ the adsorption is irreversible [40].

Since clay minerals, both natural and modified, are heterogeneous materials, the Freundlich model (Equation (11)) often fit the adsorption data properly:

$$
q=K_{f} c_{e}^{n}
$$

The Freundlich equation can also be linearized, according to Equation (12), with similar consequences as those discussed for the Langmuir equation.

$$
\log q_{e}=\log K_{F}+n \log c_{e}
$$

where $K_{F}$ is the Freundlich empirical constant $\left(\mathrm{mg} \mathrm{kg}^{-1}\right) /\left(\mathrm{mg} \mathrm{L}^{-1}\right)^{n}$, and $n$ is the dimensionless nonlinearity parameter associated with the energetic heterogeneity of the adsorption sites. The Freundlich equation, differently from the Langmuir model, cannot describe the adsorption at high adsorbate concentrations, close to the saturation of the adsorption sites.

\subsection{Partition/Distribution Coefficients}

The distribution coefficient $\left(K_{D}\right)$ can be calculated as:

$$
K_{D}=\frac{q_{e}}{c_{e}}
$$

$K_{D}$ has units of $\mathrm{L} \mathrm{g}^{-1}$ or $\mathrm{L} \mathrm{kg}^{-1}$ and can be computed for each point of the isotherm. If the affinity between the adsorbate and the clay mineral is constant for a given window of site occupation, $K_{D}$ assumes a constant value that approaches that of the Freundlich constant $\left(K_{F}\right)$ for $n=1$. In this particular case, both $K_{F}$ and $K_{D}$ approach the Henry partition constant $\left(K_{H}\right)$.

Especially for the case of organoclays, where the partition mechanism between the sorbate and the organic liquid immobilized on the clay minerals play a major role, $K_{D}$ can also be correlated and normalized to the organic carbon $(\% O C)$ content of the material, providing the $K_{O C}$ values:

$$
K_{O C}=\frac{100 K_{D}}{\% O C}
$$

The value of $K_{D}$ or $K_{O C}$ also correlates with the octanol/water coefficient $\left(K_{O W}\right)$, which measures the lipophilicity/hydrophilicity ratio of a substance under defined conditions of $\mathrm{pH}$ and temperature. Table 1 shows structures, water solubility, and $\log K_{O W}$ of commonly used pesticides. 
Table 1. Some of the pesticides that have been adsorbed onto clay minerals and their physicochemical properties.

\begin{tabular}{|c|c|c|c|c|c|}
\hline Name & Use & Structure & $\begin{array}{l}\text { Water Solubility } \\
\quad\left(\mathrm{mol} \mathrm{L}^{-1}\right)^{a}\end{array}$ & $\log K_{O W}{ }^{b}$ & $\mathrm{p} K_{a}$ \\
\hline Paraquat & Herbicide & & 3.32 & 4.50 & - \\
\hline Diquat & Herbicide & & 2.09 & 4.6 & - \\
\hline Atrazine & Herbicide & & $1.62 \times 10^{-4}$ & 2.7 & 1.7 \\
\hline Propazine & Herbicide & & $3.74 \times 10^{-5}$ & 3.95 & 1.7 \\
\hline Deethylatrazine & $\begin{array}{l}\text { Atrazine } \\
\text { metabolite }\end{array}$ & & 0.014 & 1.51 & 1.65 \\
\hline Deisopropylatrazine & $\begin{array}{l}\text { Atrazine } \\
\text { metabolite }\end{array}$ & & $3.85 \times 10^{-3}$ & 1.15 & 1.58 \\
\hline 2-Hydroxyatrazine & $\begin{array}{l}\text { Atrazine } \\
\text { metabolite }\end{array}$ & & $3.0 \times 10^{-5}$ & $\begin{array}{c}2.09 \\
(\mathrm{pH} 7.0)\end{array}$ & 5.15 \\
\hline Ametryn & Herbicide & & $8.81 \times 10^{-4}$ & 2.63 & 10.07 \\
\hline
\end{tabular}


Table 1. Cont

\begin{tabular}{|c|c|c|c|c|c|}
\hline Name & Use & Structure & $\begin{array}{l}\text { Water Solubility } \\
\qquad\left(\mathrm{mol} \mathrm{L}^{-1}\right)^{a}\end{array}$ & $\log K_{O W}{ }^{b}$ & $\mathrm{p} K_{a}$ \\
\hline Trifluralin & Herbicide & & $6.59 \times 10^{-7}$ & 5.27 & - \\
\hline Imazaquin & Herbicide & & 0.33 & 1.09 & $\begin{array}{c}3.45 \\
11.03\end{array}$ \\
\hline Fenitrothion & Insecticide & & $6.85 \times 10^{-5}$ & 3.32 & - \\
\hline Diuron & Herbicide & & $1.53 \times 10^{-4}$ & 2.87 & - \\
\hline $\begin{array}{c}1-(3,4- \\
\text { Dichlorophenyl)urea }\end{array}$ & & & $4.6 \times 10^{-3}$ & 2.65 & - \\
\hline $\begin{array}{l}\text { 1-(3,4-Dichlorophenyl)- } \\
\text { 1-methylurea }\end{array}$ & $\begin{array}{l}\text { Diuron } \\
\text { metabolite }\end{array}$ & & - & 2 & - \\
\hline 2,4-D & Herbicide & & 0.11 & 1.57 & 3.40 \\
\hline
\end{tabular}


Table 1. Cont

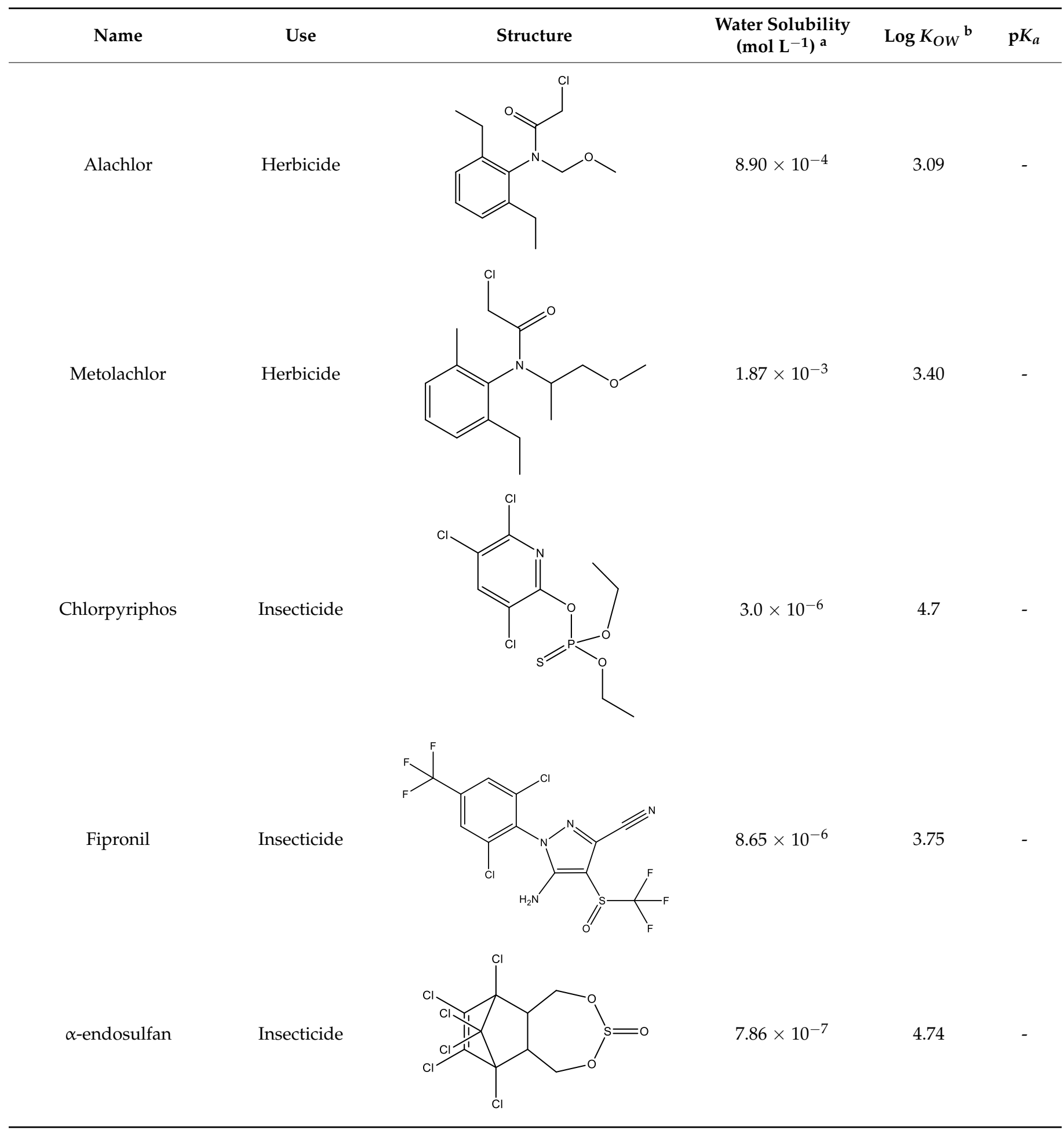


Table 1. Cont

\begin{tabular}{|c|c|c|c|c|c|}
\hline Name & Use & Structure & $\begin{array}{l}\text { Water Solubility } \\
\quad\left(\mathrm{mol} \mathrm{L}^{-1}\right)^{\mathrm{a}}\end{array}$ & $\log K_{O W}{ }^{b}$ & $\mathrm{p} K_{a}$ \\
\hline Dieldrin & Insecticide & & $5.8 \times 10^{-7}$ & 5.40 & - \\
\hline Endrin & Insecticide & & $5.8 \times 10^{-7}$ & 5.40 & - \\
\hline Imidacloprid & Insecticide & & $2.38 \times 10^{-3}$ & 0.57 & - \\
\hline Thiamethoxam & Insecticide & & 0.014 & 0.13 & - \\
\hline Thiabendazole & Fungicide & & $2.48 \times 10^{-4}$ & 2.47 & 4.64 \\
\hline Glyphosate & Herbicide & & 0.062 & 3.2 & $\begin{array}{c}2.0 \\
2.6 \\
5.6 \\
10.6\end{array}$ \\
\hline $\begin{array}{l}\text { Aminomethyl } \\
\text { phosphonic acid }\end{array}$ & $\begin{array}{l}\text { Glyphosate } \\
\text { metabolite }\end{array}$ & & 13.21 & 1.63 & $\begin{array}{c}1.8 \\
5.4 \\
10.0\end{array}$ \\
\hline 2,4-dichloroaniline & $\begin{array}{l}\text { Intermediate in } \\
\text { the production } \\
\text { of insecticides }\end{array}$ & & Not soluble & 2.78 & 2.0 \\
\hline
\end{tabular}

${ }^{\text {a }}$ Water solubility measured at $20{ }^{\circ} \mathrm{C} ;{ }^{\mathrm{b}} \log \mathrm{K}_{\mathrm{OW}}$ measured at $20^{\circ} \mathrm{C}$ and $\mathrm{pH} 7.0$ obtained from PubChem. 


\subsection{Thermodynamics and the Units Issue}

The numerical value of the fitted isotherm parameter, independent of the adsorption model, depends on the units of $c_{e}$ and $q_{e}$. The most used units are $\mathrm{mg} \mathrm{L}^{-1}\left(c_{e}\right)$ and $\mathrm{mg} \mathrm{kg}^{-1}$ or $\mathrm{mg} \mathrm{g}^{-1}\left(q_{e}\right)$, while some few works report the units as $\mu \mathrm{mol} \mathrm{L}^{-1}\left(c_{e}\right)$ and $\mu \mathrm{mol} \mathrm{kg}{ }^{-1}$ or $\mu \mathrm{mol} \mathrm{m} \mathrm{m}^{-2}\left(q_{e}\right)$. This variety of units imposes difficulties in directly comparing the adsorption parameters $\left(q_{\max }, K_{L}, K_{F}\right)$ among different adsorbates and adsorbents. Data would be much more easily comparable if $c_{e}$ and $q_{e}$ were standardized as $\mu \mathrm{mol} \mathrm{L}{ }^{-1}$ and $\mu \mathrm{mol} \mathrm{g}{ }^{-1}$ (or $\mu \mathrm{mol} \mathrm{m}^{-2}$ ). This standardization would enable the direct comparison of adsorption parameters of diverse compounds in each clay mineral or different clay minerals towards a class of compounds without considering the adsorbate's molar mass (Tables 2, 3 and 5).

Uniformization of units would also facilitate the computation of thermodynamic parameters, which help predict if physical or chemical mechanisms govern the adsorption. The following equations relate the adsorption equilibrium constant $\left(K_{C}\right)$ with standard changes of Gibbs free energy $\left(\Delta G^{0}\right)$, enthalpy $\left(\Delta H^{0}\right)$, and entropy $\left(\Delta S^{0}\right)$.

$$
\begin{gathered}
\Delta G^{0}=-R T \ln K_{C} \\
\Delta G^{0}=\Delta H^{0}-T \Delta S^{0}
\end{gathered}
$$

The Van't Hoff equation (Equation (17)) relates both Equations (15) and (16):

$$
\ln K_{C}=\frac{-\Delta H^{0}}{R T}+\frac{\Delta S^{0}}{R}
$$

where $R$ is the universal gas constant $\left(8.314 \mathrm{~J} \mathrm{~mol}^{-1} \mathrm{~K}^{-1}\right)$, and $T$ is the temperature in Kelvin. Equation (13) gives the $\Delta G^{0}$ value, while Equation (17) gives $\Delta H^{0}$ as the slope and $\Delta S^{0}$ as the intercept of the plot of $\ln K_{C}$ as a function of $1 / T$. The accuracy of the thermodynamic parameter depends on the accurate knowledge of the dimensionless $K_{C}$. Tran et al. revised the strategies for converting $K_{L}, K_{F}$, and $K_{D}$ into $K_{C}$. For instance, using Equation (18), one converts $K_{L}$ obtained in an aqueous medium with $\mathrm{L} / \mathrm{mmol}$ units into the dimensionless $K_{C}[28,41,42]$ :

$$
K_{C}=55.5 \times 1000 \times K_{L}
$$

The factor 55.5 is the number of moles of pure water per liter, and the factor 1000 converts mmol into mol.

The Freundlich constant $K_{F}$ can provide the dimensionless $K_{C}$ by Equation (19):

$$
K_{C}=\frac{K_{F} \rho}{1000}\left(\frac{10^{6}}{\rho}\right)^{\left(1-\frac{1}{n}\right)}
$$

where $\rho$ is the density of pure water $(1.0 \mathrm{~g} / \mathrm{mL})$.

Because $K_{F}$ relies on the concentrations of both liquid-phase $\left(c_{e}, \mathrm{mg} / \mathrm{L}\right.$ or $\left.\mathrm{mmol} / \mathrm{L}\right)$ and solid-phase $\left(q_{e}, \mathrm{mg} / \mathrm{g}\right.$ or $\left.\mathrm{mmol} / \mathrm{g}\right)$, these differing units reciprocally convert into each other by Equation (20):

$$
K_{F}=K_{F}^{\prime}\left(M_{W}\right)^{1-1 / n}
$$

where $M_{W}$ is the molar mass of the adsorbate, $K_{F}$ is the Freundlich constant expressed as $(\mathrm{mg} / \mathrm{g}) /(\mathrm{mg} / \mathrm{L})^{1 / n}$ and $K_{F}^{\prime}$ the same constant in $(\mathrm{mmol} / \mathrm{g}) /(\mathrm{mmol} / \mathrm{L})^{1 / n}$ units $[28,43]$.

Tran et al. also reviewed how to compute the dimensionless $K_{C}$ value from the partition and distribution coefficients, $K_{P}$ and $K_{D}$, respectively [28]. In summary, reliable thermodynamic parameters require that the adsorption experiment reach the chemical equilibrium, using different temperatures and a wide range of initial adsorbate concentrations. The experimental conditions must be described in detail, providing the adsorption data $\left(q_{e}\right.$ vs. $\left.c_{e}\right)$ and the fitting to the adsorption models. 


\subsection{The Analytical Measurements}

Detailed kinetic and thermodynamic characterization demands many experiments. Thus, analytical methods with high sampling throughput, high sensitivity, and detectability with a wide linear dynamic range are necessary for these studies. In several works, the solution phase is directly analyzed by UV (ultraviolet) spectrophotometry. However, from the authors' own experience, these measurements are not adequate, especially if low concentrations are under study, aiming to characterize the adsorption isotherms and kinetic at a low degree of site occupation. During the equilibration, the aqueous phase extracts small amounts of UV-absorbing matrix components, causing errors in the adsorption interpretation. Chromatographic techniques circumvent the interference caused by polar UV-absorbance substances since they are separated from the target adsorbate.

Nowadays, liquid chromatography methods to investigate adsorption/desorption of herbicides benefit from modern short columns packed sub-2- $\mu \mathrm{m}$ porous particles or fused-core particles to achieve high sample throughput and low consumption of solvents, providing high selectivity. The high sample throughput is essential to enable the construction of detailed kinetic and adsorption/desorption curves.

\section{Natural Homoionic Clay Minerals as Pesticide Adsorbents}

Adsorption of pesticides onto natural clay mineral relies on the use of adsorbents with minimal treatment beyond their preparation to provide a narrow size distribution and homoionic form by exchanging the naturally occurring interlamellar cations (in the case of smectites) by some alkaline $\left(\mathrm{Na}^{+}\right.$or $\left.\mathrm{K}^{+}\right)$or alkaline earth $\left(\mathrm{Ca}^{2+}\right.$ or $\left.\mathrm{Mg}^{2+}\right)$ cation. The adsorption capacity and strength of pesticides onto homoionic clay minerals depend on the chemical nature of the pesticide, surface area, and pore volume. Electrostatic interactions, hydrogen and coordinative bonds, surface complexations, and hydrophobic associations are the main interactions between pesticides and clay minerals [44]. Cation exchange, for instance, is the primary retention mechanism for cationic pesticides such as paraquat, diquat, and difenzoquat on natural and modified clays [13,45-49]. For instance, adsorption isotherms of terbutryn (basic), dicamba (anionic), and paraquat on natural and modified clays from Morocco revealed that the natural clay efficiently adsorbed paraquat from aqueous solutions (Table 2).

In contrast, terbutryn and dicamba required the modification of the clays with longchain organic cations such as octyltrimethylammonium (OTMA) or octadecyltrimethylammonium (ODTMA) [45]. These studies adopted $24 \mathrm{~h}$ of contact time to construct the adsorption isotherms without a more detailed kinetic investigation. Since paraquat is a quaternary ammonium cation, its dual positive charges are not affected by the solution $\mathrm{pH}$, contrary to terbutryn and dicamba.

Seki and Yurdakoç compared the adsorption of paraquat on sepiolite, bentonite, and illite before and after modification with nonyl- and dodecylammonium chlorides [50]. These studies adopted $24 \mathrm{~h}$ of contact time, also without investigating the adsorption kinetics (Table 2). Compared with the Freundlich equation, the Langmuir model provided the best data fitting, consistent with the specific cation exchange mechanism. Among the non-modified clay minerals, illite exhibited the highest adsorption capacity, followed by bentonite and sepiolite. The $q_{\max }$ and $K_{L}$ for adsorption on natural illite and nonylammonium chloride modified illite were of similar magnitude, provided without standard deviations. Modification of illite and bentonite with dodecylammonium cation decreased both $q_{\max }$ and $K_{L}$ compared to the natural clay mineral.

Shattar et al. studied the adsorption of the herbicide ametryn (a triazine) onto an acid-activated natural clay mineral [51] and commercial montmorillonite [52,53], testing the classical kinetic adsorption isotherm models. Since the pKa of ametryn is 4.1 (Table 1), it is positively charged at $\mathrm{pH}<\mathrm{pKa}$ because of the protonation of the isopropylamine and ethylamine groups, thus favoring electrostatic interaction and ion exchange retention processes with the clay mineral. This hypothesis was confirmed by performing adsorption experiments in the $\mathrm{pH}$ range between 2 and 12, with the highest adsorbed loads found at 
pH 2.0 [51,52]. Despite the demonstrated importance of $\mathrm{pH}$, the authors did not specify the $\mathrm{pH}$ at which they performed the kinetic, isothermal, and thermodynamic experiments. The adsorption was fast and reached equilibrium within less than $6 \mathrm{~h}$ of contact time. The pseudo-second-order model best fitted the kinetic data, consistent with the chemisorption ion exchange process. The intraparticle diffusion model was the limiting adsorption rate at the shortest contact times since the plot of $q_{t}$ versus $t^{0.5}$ passed through the origin. Among the several isotherm models investigated (Langmuir, Freundlich, Temkin, and Redlich-Peterson), the Langmuir provided the best fitting suggesting that ametryn formed a homogeneous monolayer over the clay mineral surface. The commercial montmorillonite provided significantly higher $q_{\max }\left(189 \mathrm{mg} \mathrm{g}^{-1}\right)$ than the acid-activated natural clay $\left(85.16 \mathrm{mg} \mathrm{g}^{-1}\right)$. The thermodynamic parameters were straightforwardly computed from the distribution coefficient $K_{D}$, computed as:

$$
K_{D}=\frac{c_{A, e}}{c_{e}}
$$

where $c_{A, e}$ is the concentration of adsorbed ametryn at equilibrium $\left(\mathrm{mg} \mathrm{L}^{-1}\right)$ and $c_{e}$, the solution concentration, also in $\mathrm{mg} \mathrm{L}^{-1}$, thus providing a dimensionless $K_{D}$ to be used as $K_{C}$ in Equation (15). Equation (21) considers the adsorption system as homogeneous to convert $q_{e}$ into $c_{A, e}$. The negative values of $\Delta G$ was consistent with the spontaneous ionic interaction. None of these works studied the desorption kinetics and isotherms.

Nonionic pesticides such as deltamethrin adsorb onto bentonite in natural or cellulosemodified forms with similar $q_{\max }$ values (between 36.39 and $36.74 \mathrm{mg} \mathrm{g}^{-1}$; no standard deviation provided) best fitting to the Langmuir and the pseudo-second-order kinetic rate [54] (Table 2). Since deltamethrin is nonionic, cation exchange is not involved. Thus, hydrogen bonding and van der Waals interactions play a crucial role in adsorption at the external surfaces of the clay minerals.

Abate and Masini studied the adsorption of atrazine (AT) and the atrazine metabolites hydroxyatrazine (HAT), deisopropylatrazine (DIA), and deethylatrazine (DEA) onto homoionic $\left(\mathrm{K}^{+}\right)$montmorillonite $(\mathrm{KMt})$ and vermiculite $(\mathrm{KVt})$ [2]. Montmorillonite adsorbed more than $99.5 \%$ of AT, HAT, and DIA from 0.050 to $1.0 \mathrm{mg} \mathrm{L}^{-1}$ solutions. With this high adsorption percentage (adopting an arbitrary $24 \mathrm{~h}$ contact time), it was impossible to fit data to any adsorption isotherm model because the $c_{e}$ values were lower than the detection limits of the HPLC-UV analytical method. In these experiments, an arbitrary $30 \mathrm{mg}$ to $3.0 \mathrm{~mL}$ solid to solution ratio was adopted, being a typical example that, to construct adsorption isotherms and adsorption kinetics, much lower ratios should have been used to quantify the quantification of $c_{e}$ values. Alternatively, a much more sensitive analytical technique such as HPLC-MS/MS should have been used. Montmorillonite, however, removed 72 to $64 \%$ of deethylatrazine (DEA), and the adsorption data fitted the Freundlich equation (Table 2). The adsorption data of the triazines on $\mathrm{KVt}$ were reasonably fitted by the Freundlich model $\left(R^{2}>0.99\right)$, excepting deethylatrazine $\left(R^{2}=0.87\right)$, for which the adsorption was negligible (here, a higher solid to solution ratio would be helpful). The adsorption of the triazine compounds was assigned to hydrogen bonding and van der Waals interactions because all the compounds were in their neutral forms at the $\mathrm{pH}$ studied (7.14 for KVt and 6.3 for KMt) [2]. The surface area and pore volume of KMt $\left(228 \mathrm{~m}^{2} \mathrm{~g}^{-1}\right.$ and $\left.97 \mu \mathrm{L} \mathrm{g}^{-1}\right)$ were significantly higher than that of $\mathrm{KVt}\left(31.4 \mathrm{~m}^{2} \mathrm{~g}^{-1}\right.$ and $\left.14 \mu \mathrm{L} \mathrm{g}^{-1}\right)$, explaining its better adsorption performance. The adsorption percentage increased by lowering the initial $\mathrm{pH}$, which led to protonation of the triazines and favored the ion exchange and electrostatic interaction mechanisms. The high adsorption on KMt and the desorption in organic solvents such as acetonitrile motivated the development of a dispersive solid-phase extraction procedure aiming at preconcentrating triazine herbicides from river waters before chromatographic analysis [25]. The KMt could be reused without loss of performance at least one more time. However, the number of possible reuses was not demonstrated [2,25]. 
Glyphosate is currently the most used herbicide worldwide, and its effects on human health and environmental balance have been the subject of intense debate [55]. At the typical soil $\mathrm{pH}$, the glyphosate and its primary metabolite, the aminomethylphosphonic acid (AMPA), occur in anionic form, so they are not likely to interact electrostatically with clay minerals surface. On the other hand, the carboxylate, amine, and phosphonate groups make them chelating substances that interact with surface-bound metal ions such as $\mathrm{Fe}(\mathrm{III}), \mathrm{Fe}(\mathrm{II}), \mathrm{Ca}(\mathrm{II})$, $\mathrm{Mg}(\mathrm{II})$. Pereira et al. investigated the adsorption of glyphosate onto Mt in the artificial seawater and different saline solutions, noticing that the complexation of $\mathrm{Ca}$ (II) by glyphosate enhanced the adsorption onto the clay mineral to a larger extension than complexation with $\mathrm{Mg}$ (II) or $\mathrm{Na}^{+}$[56]. Thus, the glyphosate chelating functionalities interact with Mt via surface complexation with metal cations and silanol/hydroxyl groups [49,56]. No kinetic investigation was undertaken, and the adsorption experiments adopted $24 \mathrm{~h}$ contact time, best fitting the one-or two-site Sips isotherm [56]. Because glyphosate has excess negative charges at $\mathrm{pH} 7.0$, it cannot easily penetrate the interlayer space. At $\mathrm{pH} 4.0$, however, the protonated amine group favors electrostatic interactions with interlayer negative charges, but as the $\mathrm{pH}$ decreases to values $<3$, both glyphosate and Mt become positively charged, reducing the adsorption, as demonstrated by Khoury et al. [57] (Table 2). Surface complexation by forming metal bridges and hydrogen bonding explained the adsorption of other anionic species such as humic substances on vermiculite [58,59]. 
Table 2. Sorbent characterizations and sorption features of pesticides and metabolites onto natural clay minerals.

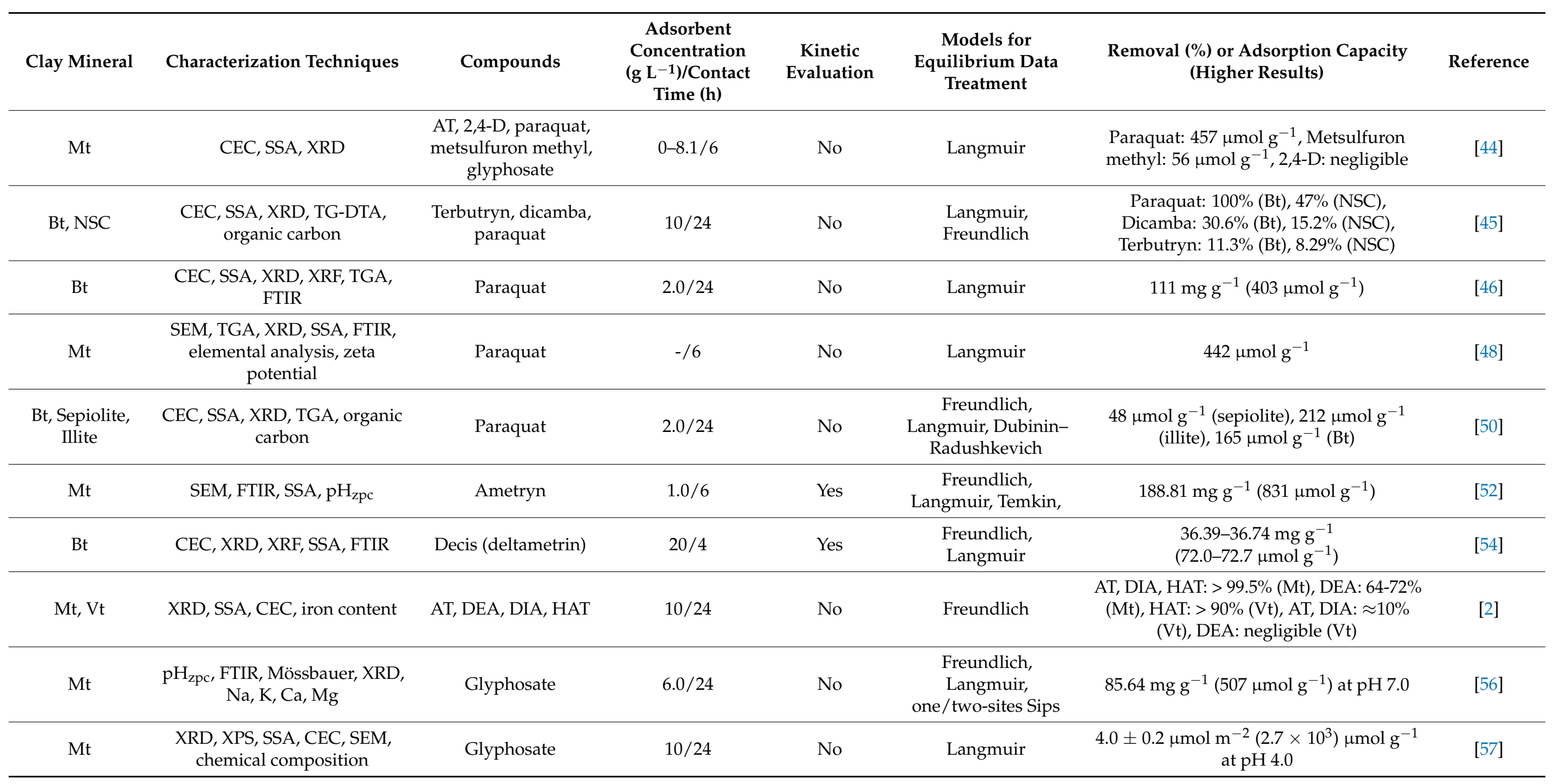

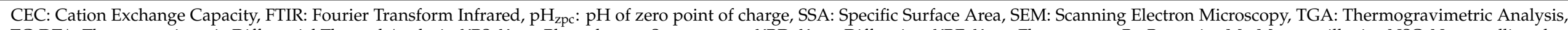

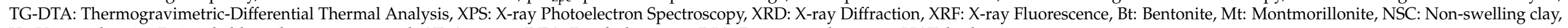

Vt: Vermiculite, 2,4-D: 2,4-dichlorophenoxyacetic acid, AT: Atrazine, DEA: Deethylatrazine, DIA: Deisopropylatrazine, HAT: hydroxyatrazine. 


\section{Organophilic Clay Minerals}

Exchange of the inorganic interlayer cations by cationic or zwitterionic surfactants keep apart the aluminosilicate layers, resulting in increased basal spacing and hydrophobicity, thus enhancing the affinity toward neutral organic compounds with poor water solubility or high $K_{O W}$ values [14,60]. Examples of organic cations appear in Figure 1, and some relevant applications to removing pesticides from aqueous media are highlighted in Table 3. Since $\log \mathrm{K}_{\mathrm{OW}}$ is $\mathrm{pH}$-dependent, proper $\mathrm{pH}$ control and reporting are mandatory in adsorption studies, especially for interpreting the adsorption behavior of ionizable pesticides. In their neutral forms, the magnitude of adsorption constants correlates with the $K_{O W}$. For instance, in organophilic kaolinite and bentonite, the $K_{d}$ values increased in the order atrazine (log $\left.K_{O W}=2.61\right)<$ alachlor $\left(\log K_{O W}=3.52\right)<$ trifluralin $\left(\log K_{O W}=5.34\right)$ [61]. The size of the alkyl chain of organic cation and the amount incorporated into the clay gallery strongly affect the adsorbent's hydrophobicity, enabling a fine-tuning in the treatment of the mineral phase to attend to the application needs.

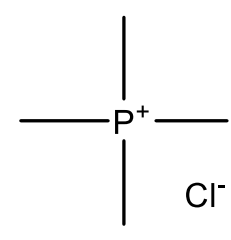

1

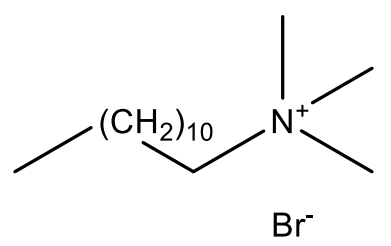

2<smiles>CCC[NH3+]</smiles>

5

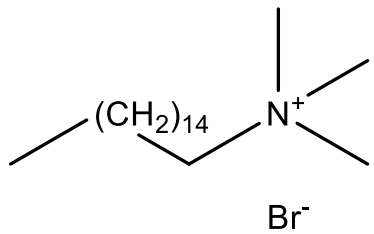

3
6

4<smiles>CCCCCCCC/C=C/CCCCCC[NH+](C)C</smiles>

7

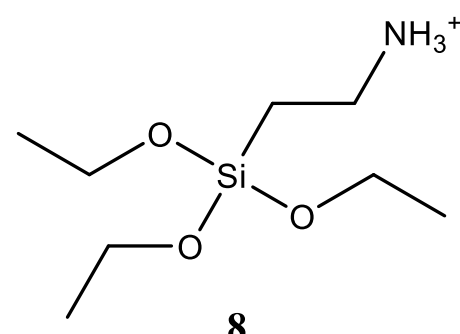

Figure 1. Some examples of organic cations used to produce organoclays: 1-tetramethyl phosphonium chloride; 2-dodecyltrimethylammonium bromide (DDTMA), 3-hexadecyltrimethylammonium bromide (HDTMA), 4didodecyltrimethylammonium bromide (DDDTMA), 5-dodecylamine (DDA), 6-octadecyl amine (ODA), $7-\mathrm{C}_{14}-\mathrm{C}_{18}$ unsaturated dimethyl dialkyl amine (DDA), 8-Aminopropyltriethoxysilane (APTES).

Abate and Masini [21] intercalated $\mathrm{K}^{+}$homoionic vermiculite (KVt) with hexadecyltrimethylammonium (HDTMA) aiming at the adsorption of fulvic acid [31,62] and the triazine herbicides propazine (PRO) and atrazine and the metabolites HAT, DEA, and DIA from aqueous media. The cation exchange capacity (CEC) drove the vermiculite modification design so that the amount of HDTMA used in the modification corresponded to 50 and $100 \%$ of CEC. The modified materials were denoted as HDTMA-Vt $t_{0.5}$ and HDTMA-Vt $t_{1.0}$, respectively. The modification increased the basal spacing (d001) from $1.08 \mathrm{~nm}(\mathrm{KVt})$ to $1.37 \mathrm{~nm}\left(\mathrm{HDTMA}-\mathrm{Vt}_{0.5}\right)$ and $1.44 \mathrm{~nm}\left(\mathrm{HDTMA}-\mathrm{Vt}_{1.0}\right)$. On the other hand, the BET sur- 
face area reduced from $31.4 \mathrm{~m}^{2} \mathrm{~g}^{-1}(\mathrm{KVt})$ to 13.7 and $11.4 \mathrm{~m}^{2} \mathrm{~g}^{-1}$ for HDTMA-Vt $\mathrm{t}_{0.5}$ and HDTMA-Vt $t_{1.0}$, respectively. These results were consistent with the HDTMA hindering the access $\mathrm{N}_{2}$ to the interlamellar space of the clay mineral, and the elemental analysis confirmed the incorporation of $\mathrm{C}, \mathrm{H}$, and $\mathrm{N}$ in the structure. No kinetic studies were performed, and the adsorption isotherms were constructed using an arbitrary contact time of $24 \mathrm{~h}$. Thus, it is not possible to state that the results correspond to the equilibrium situation. From the $\mathrm{pKa}$ of the compounds (Table 1), only HAT partially protonates (about $1 \%$ ) at the $\mathrm{pH} 7.1$ adopted in the adsorption experiments, whereas the other compounds were neutral. Adsorption of AT, DEA, DIA, and PRO from a mass to volume ratio of $30 \mathrm{mg}$ to $3.0 \mathrm{~mL}$ was negligible in $\mathrm{KVt}$, contrary to HAT. The linearized Freundlich model (Equation (12)) properly fitted the adsorption data $\left(25^{\circ} \mathrm{C}\right)$, and the $n$ value close to 1 indicated that partition is the primary adsorption mechanism, consistent with modification with HDTMA (Table 4). Intercalating HDTMA into the vermiculite structure significantly enhanced PRO, AT, DEA, and DIA adsorption affinity compared with the unmodified counterpart (KVt). The $K_{\mathrm{F}}$ values were systematically higher for HDTMA-Vt $\mathrm{t}_{1.0}$ than for HDTMA-Vt $\mathrm{t}_{0.5}$ (Table 4).

Additionally, the $K_{\mathrm{F}}$ increased with the hydrophobicity of the compounds (Table 1), confirming that the modification of vermiculite with HDTMA produced the expected effect on the affinity toward the studied triazines. On the other hand, the organophilization of KVt decreased the HAT adsorption because the primary binding mechanisms for this metabolite are electrostatic attraction and hydrogen bonding to the silanol groups of the clay surface [21]. Another piece of information from this article is that the adsorption on HDTMA-modified vermiculite is predominantly reversible; consequently, this material has potential application in the production of controlled release herbicide formulations.

Montmorillonite is more used than vermiculite, having a larger surface area, although with lower cation exchange capacity. Park et al. exchanged montmorillonite with HDTMA, dodecyltrimethylammonium bromide (DDTMA), and didodecyltrimethylammonium bromide (DDDTMA) to investigate the removal of atrazine and imazaquin from aqueous samples in single-component and mixed solutions [63]. While the unmodified montmorillonite did not remove the pesticides, the organoclays removed $93.1 \%$ of imazaquin and $47.1 \%$ of atrazine (Table 3). The size and amount of incorporated organocation influenced the adsorption percentages. Larger cations (DDDTMA) and higher amounts (1.0, 1.5 , or 2.0 times the CEC of montmorillonite) increased the adsorption percentage. This behavior was assigned to increase the basal spacing provided by the larger cations in incorporated amounts. Kinetic experiments suggested that equilibrium reached within $2 \mathrm{~h}$ of contact time. Linearized pseudo-second-order best fitted the data in comparison with the pseudo-first-order model. Adsorption on materials modified with smaller organic cations (DDTMA) exhibited higher $k_{2}$, thus reaching the equilibrium faster than those modified with larger cations. Pore blocking is a possible explanation for this slower adsorption, but the higher adsorption percentages in DDDTMA-modified materials suggest that diffusion through the organic layer controls the rate of accessing specific adsorption sites. Testing the intraparticle diffusion model would help elucidate the adsorption mechanism. The Freundlich equation best fitted the adsorption data for imazaquin, whereas the Langmuir model worked better for atrazine. Independent of the model and material, the affinity for imazaquin was higher than for atrazine. A synergistic effect appeared in the mixed solutions enhancing the adsorption of both compounds, especially atrazine. Since imazaquin is a zwitterionic compound with pKa 3.8 (carboxylic group) and 2.0 (quinoline group), its adsorption was much more influenced by the solution $\mathrm{pH}$ than atrazine ( $\mathrm{pKa} 1.64$ ) in the $\mathrm{pH}$ range between 2 and 7 , with the highest $q_{e}$ values in $\mathrm{pH} 3$ to 5 . Carboxylate negative charges prevail at $\mathrm{pH}>5$, and positive charges appear at $\mathrm{pH}>3$ due to the protonation of quinoline groups, decreasing the adsorbed concentrations. Different from imazaquin, atrazine remains neutral in the studied $\mathrm{pH}$ range.

A recent work by Oiwa et al. demonstrated that didodecyldimethylammonium bromide montmorillonite (DDDTMA) organoclay adsorbed more than $90 \%$ of the organophosphorus pesticide fenitrothion $\left(\log K_{O W}=3.43\right)$ in about $10 \mathrm{~min}$. The modification in- 
creased the basal spacing from 1.55 to $3.15 \mathrm{~nm}$. In comparison, the unmodified clay mineral removed only about $30 \%$ in a wide $\mathrm{pH}$ range between 5 and 9 . Interestingly, the organoclay mediated the degradation of fenitrothion to the less toxic compound 3methyl-4-nitrophenol as determined by LC/MS after extraction of the adsorbent with acetonitrile [64].

Manzotti et al. evaluated the adsorption of atrazine, ametrine, diuron, and 2,4-D onto commercial organophilic bentonite. Since this is commercial material (Spectrogel, from SpectroChem Company, Brazil), the modifier composition used to produce the organophilic adsorbent is unknown [26]. The kinetic studies indicated that intraparticle diffusion is the rate-limiting adsorption step, reaching equilibrium with about $480 \mathrm{~min}$ of contact time in a batch experiment, but all the adsorption isotherms adopted $24 \mathrm{~h}$ of contact time. The isotherms exhibited a concave shape, with a steeper slope under the lower initial concentrations without reaching a plateau (L-shaped isotherm according to the Giles classification [65]). This result suggests that adsorption on specific sites, in addition to partition, governs the adsorption, as denoted by the Langmuir model best fitting the experimental data (Table 3). Diuron and ametrine exhibited the larger $q_{\max }$ values, but this information must be viewed with care because the partition mechanism seems to prevail for these compounds, especially for the case of diuron $(n=1.313)$. With $n$ approaching the unity, the Freundlich $K_{F}$ parameter approaches the Henry constant, so the $q_{\max }$ becomes overestimated. Unfortunately, the authors do not specify the $\mathrm{pH}$ of the adsorption experiments, making difficult a discussion on the effect of ionization on the adsorption efficiency.

Saha et al. studied the batch adsorption of mixed chlorinated pesticides (alachlor, metolachlor, chlorpyriphos, fipronil, $\alpha$-endosulfan, $\beta$-endosulfan, $p, p^{\prime}$-DDT, and two metabolites $p, p^{\prime}$-DDE and endosulfan sulfate) on commercial organo-montmorillonite modified with octadecylamine (ODA-Mt), dimethyldialkylamine (DDA-Mt) and octadecylamine, and aminopropyltriethoxysilane (ODAAPS-Mt) [66] (Table 3). Gas chromatography with capillary columns enabled baseline separations, and an Electron Capture Detector (ECD) provided high sensitivity measurements. Fast adsorption removed $5080 \%$ of all the pesticides within 90 min of contact time, with the linearized pseudo-second-order kinetic model best fitting the experimental data. The authors did not investigate if intraparticle diffusion was the rate-limiting adsorption step. Chlorpyriphos, $p, p^{\prime}$-DDT, and $p, p^{\prime}$-DDE exhibited faster adsorption in agreement with their higher $\log K_{O W}$ and lower water solubility, confirming the organophilic character of the three modified montmorillonites. The adsorption isotherms measured with $480 \mathrm{~min}$ of contact time were fitted only by the Freundlich equation, with $\mathrm{r}^{2}>0.95$ for all compounds and adsorbents. The $1 / n$ values varied from 0.14 (alachlor in ODAAPS-Mt) to 0.51 (-endosulfan in ODA-Mt), indicating a high magnitude of the adsorption driving force, as well as high heterogeneity. The $K_{F}$ values were strongly correlated with the $\log K_{O W}$, demonstrating the importance of hydrophobic interactions governing the adsorption, in agreement with the kinetic studies. The adsorption performance of the modified montmorillonites was not compared with that of the unmodified clay mineral, challenging the evaluation of the effect of organic cations intercalation on the pesticides adsorption. Among the modified materials, the ODAAPS-Mt exhibited higher $K_{F}$ values. However, as in most adsorption studies found in the literature, the authors did not express the $K_{F}$ and $1 / n$ values with standard deviations. Consequently, from a statistical point of view, it is not safe to state that the $K_{F}$ values found for ODAAPS-Mt are significantly higher than those for the other adsorbents. The $K_{F}$ values were erroneously discussed as adsorption capacities, expressed with units of $\mathrm{mg} \mathrm{g}^{-1}$. Additionally, since there is no comparison between adsorption parameters obtained in the mixture with that of individual compounds, it is impossible to take a more deep conclusion on the competitive phenomenona that may occur in these situations [66]. 
Table 3. Sorbent characterizations and sorption features of pesticides and metabolites onto organically modified clay minerals.

\begin{tabular}{|c|c|c|c|c|c|c|c|}
\hline Clay Mineral & $\begin{array}{l}\text { Characterization of the } \\
\text { Adsorbents }\end{array}$ & Compounds & $\begin{array}{c}\text { Adsorbent } \\
\text { Concentration } \\
\left(\mathrm{g} \mathrm{L}^{-1}\right) / \text { Contact } \\
\text { Time (h) }\end{array}$ & $\begin{array}{l}\text { Kinetic } \\
\text { Evaluation }\end{array}$ & $\begin{array}{l}\text { Models for } \\
\text { Equilibrium Data } \\
\text { Treatment }\end{array}$ & $\begin{array}{c}\text { Removal (\%) or Adsorption Capacities } \\
\text { (Higher Results) }\end{array}$ & Reference \\
\hline $\begin{array}{l}\text { Commercial } \\
\text { organophilic Bt }\end{array}$ & $\begin{array}{l}\text { SEM-EDX, SSA, TG-DSC, } \\
\text { XRF, FTIR }\end{array}$ & $\begin{array}{l}\text { AT, ametryn, 2,4-D, } \\
\text { diuron }\end{array}$ & $5.0 / 24$ & Yes & $\begin{array}{l}\text { Langmuir, Freundlich, } \\
\text { Temkin }\end{array}$ & $\begin{array}{l}\text { AT: 10.5, ametryn: 111, diuron: 202, 2,4-D: } \\
\qquad 29 \mu \mathrm{mol} \mathrm{g}^{-1}\end{array}$ & [26] \\
\hline $\begin{array}{l}\text { Bt and NSC modified } \\
\text { with ODTMA, TMA, } \\
\text { OTMA }\end{array}$ & $\begin{array}{l}\text { CEC, XRD, SSA, TG-DTA, } \\
\text { Organic carbon }\end{array}$ & $\begin{array}{l}\text { Terbutryn, dicamba, } \\
\text { paraquat }\end{array}$ & $10 / 24$ & No & Langmuir, Freundlich & $\begin{array}{c}\text { Paraquat: 100\% (TMA-Bt), 47\% (TMA-NSC), } \\
\text { Dicamba: 76.6\%, (ODTMA-Bt), } 35.5 \% \\
\text { (ODTMA-NSC), Terbutryn: } 95.4 \% \\
\text { (ODTMA-Bt), 86.5\% (ODTMA-NSC) }\end{array}$ & [45] \\
\hline $\begin{array}{l}\text { Bt, Sepiolite and Illite } \\
\text { modified with DDA } \\
\text { and NA }\end{array}$ & $\begin{array}{l}\text { CEC, SSA, XRD, TGA, } \\
\text { organic carbon }\end{array}$ & Paraquat & $2.0 / 24$ & No & $\begin{array}{l}\text { Freundlich, Langmuir, } \\
\text { Dubinin-Radushkevich }\end{array}$ & $\begin{array}{c}95 \mu \mathrm{mol} \mathrm{g}{ }^{-1} \text { (Illite-DDA), } 223 \mu \mathrm{mol} \mathrm{g}^{-1} \\
\text { (Illite-NA) }\end{array}$ & [50] \\
\hline Kt-TMA, Bt-TMA & $\begin{array}{l}\text { CEC, SSA, total organic } \\
\text { carbon, elemental analysis }\end{array}$ & $\mathrm{AT}$, alachlor, trifluralin & $25 / 548$ & No & Freundlich & $\begin{array}{l}\text { AT: } 69.8 \% \text { (Bt-TMA), Alachlor: } 63.0 \% \\
\text { (Kt-TMA), Trifluralin: } 65.0 \% \text { (Kt-TMA) }\end{array}$ & [61] \\
\hline Vt-HDTMA & $\begin{array}{l}\text { XRD, SSA, iron content, } \\
\text { elemental analysis }\end{array}$ & Fulvic Acid & $10 / 24$ & No & - & 74 and $98 \%$ & {$[62]$} \\
\hline Mt-DDDMA & $\begin{array}{c}\text { SEM, SSA, FTIR, XRF, } \\
\text { XRD, }\end{array}$ & Fenitrothion & $0.4 / 0.25$ & No & Freundlich, Langmuir & $68.5 \pm 1.2 \mathrm{mg} \mathrm{g}^{-1}\left(247 \pm 4 \mu \mathrm{mol} \mathrm{g}^{-1}\right)$ & [64] \\
\hline $\begin{array}{l}\text { Mt-ODA, Mt-DMDA, } \\
\text { Mt-ODAAPS }\end{array}$ & FTIR, XRD, SEM-EDX & $\begin{array}{l}\text { chlorpyriphos, } p, p^{\prime} \text {-DDT } \\
p, p^{\prime} \text {-DDE, endosulfan } \\
\text { sulphate, } \alpha \text { - } \beta \text {-endosulfan, } \\
\text { alachlor, metolachlor, } \\
\text { fipronil }\end{array}$ & $10 / 8$ & Yes & Freundlich & 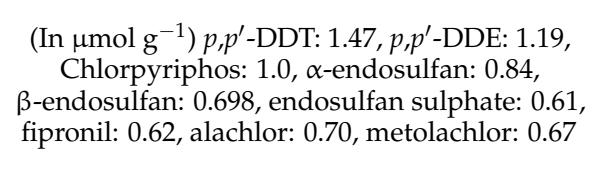 & [66] \\
\hline $\begin{array}{l}\text { Mt-carboxy methyl } \\
\text { cellulose-DMDA }\end{array}$ & XRD, SEM-EDX, FTIR & $\begin{array}{l}\text { AT, imidacloprid, } \\
\text { thiamethoxam }\end{array}$ & $10 / 4$ & No & Freundlich, Langmuir & $\begin{array}{c}\text { Imidacloprid: } \\
8.82, \text { thiamethoxam: } 5.71, \mathrm{AT} \text { : } \\
6.63 \mu \mathrm{mol} \mathrm{g}^{-1}\end{array}$ & [67] \\
\hline
\end{tabular}

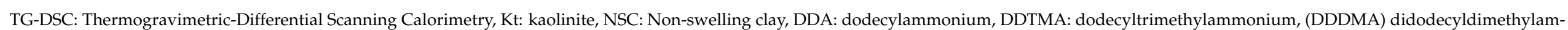

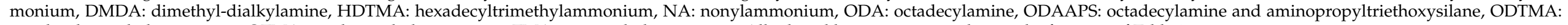
octadecyltrimethylammonium, OTMA: octyltrimethylammonium, TMA: tetramethylammonium. All other abbreviations according to the footnote of Table 2. 
Table 4. Chemical properties and Freundlich parameters, $K_{\mathrm{F}}\left(\mu \mathrm{mol}{ }^{1 \mathrm{n}} \mathrm{L}^{\mathrm{n}} \mathrm{kg}^{1}\right)$ found for the adsorption of atrazine (AT), propazine (PRO), deethylatrazine (DEA), deisopropylatrazine (DIA), and hydroxyatrazine (HAT) onto HDTMA modified vermiculite [21].

\begin{tabular}{|c|c|c|c|c|c|c|c|c|c|}
\hline \multirow{3}{*}{ Compound } & \multicolumn{9}{|c|}{ Materials } \\
\hline & \multicolumn{3}{|c|}{ HDTMA-Vt $_{0.5}$} & \multicolumn{3}{|c|}{ HDTMA-Vt 1.0} & \multicolumn{3}{|c|}{ KVt } \\
\hline & $1 / n$ & $K_{F}$ & $R^{2}$ & $1 / n$ & $K_{F}$ & $R^{2}$ & $1 / n$ & $K_{F}$ & $R^{2}$ \\
\hline AT & $1.02 \pm 0.02$ & $102 \pm 3$ & 0.999 & $1.08 \pm 0.01$ & $138 \pm 2$ & 0.999 & $0.90 \pm 0.05$ & $10.5 \pm 0.7$ & 0.992 \\
\hline PRO & $0.97 \pm 0.01$ & $214 \pm 5$ & 0.999 & $0.97 \pm 0.02$ & $355 \pm 17$ & 0.998 & & & \\
\hline DEA & $0.97 \pm 0.02$ & $50 \pm 1$ & 0.997 & $0.99 \pm 0.02$ & $81 \pm 2$ & 0.997 & $0.8 \pm 0.2$ & $0.45 \pm 0.10$ & 0.87 \\
\hline DIA & $0.98 \pm 0.05$ & $20 \pm 1$ & 0.986 & $0.90 \pm 0.02$ & $35 \pm 1$ & 0.998 & $0.93 \pm 0.04$ & $16.6 \pm 0.8$ & 0.994 \\
\hline HAT & $1.07 \pm 0.01$ & $14.8 \pm 0.7$ & 0.993 & $1.00 \pm 0.02$ & $21.9 \pm 0.4$ & 0.998 & $0.51 \pm 0.03$ & $(1.2 \pm 0.1) \times 10^{3}$ & 0.997 \\
\hline
\end{tabular}

Adsorption of atrazine, imidacloprid, and thiamethoxam onto carboxymethyl cellulose nano montmorillonite modified with $35-45 \mathrm{wt} \%$ dimethyl dialkyl $\left(\mathrm{C}_{14}-\mathrm{C}_{18}\right)$ amine was fitted to Freundlich and Langmuir isotherms in their nonlinear and linearized forms. The contact time of $4 \mathrm{~h}$ was used to obtain the isotherms, although no kinetic experiment demonstrated enough time to reach the adsorption equilibrium. Four linearized forms of the Langmuir equations produced different values of $K_{L}$ and $q_{\max }$. However, the order of affinity and capacity was the same, independent of the equation: imidacloprid $>$ thiamethoxam $>$ atrazine. The $K_{F}$ was erroneously treated as an adsorption capacity parameter, with units of $\mu \mathrm{g} \mathrm{g}^{-1}$, even with $1 / n$ between 0.80 and 0.90 . Error parameters analyzed by nonlinear regression avoided the bias resulting from linearization, demonstrating that the nonlinear regression provided more effective error minimization and the Langmuir model fitted the data better than the Freundlich equation. Although this work performed a detailed statistical evaluation of errors, it does not provide standard deviations for the parameters fitted by the Langmuir and Freundlich models [67].

\section{Intercalated and Pillared Clay Minerals}

Intercalating and pillaring clay minerals consist of exchanging the interlayer cation $\left(\mathrm{K}^{+}, \mathrm{Na}^{+}, \mathrm{Ca}^{2+}\right)$ by a polynuclear hydroxyl metal cation (intercalating), followed by thermal treatment to obtain a series of oxide pillars between the layers of the clay mineral structure. Relevant applications and the results of using intercalated or pillared clay minerals to remove pesticides from aqueous media appear in Table 5. There have been papers on the pillarization principles since 1955 [68], and the first reports on the preparation of pillared clays date between the 1970s and 1980s, based on the use of aluminum polycations for intercalation of smectites, producing pillared materials with high basal spacing and thermal stability up to $500{ }^{\circ} \mathrm{C}$ [69]. Thermal treatments convert the polycations into oxides, preventing structural collapse [70]. Compared with the raw clay mineral, the pillars provide the acidic sites in the interlayer surfaces and a more porous structure, besides an increase in the surface area and changes in the charge properties, affording diverse adsorption mechanisms of organic compounds [70-72]. The treatment consists of the exchange of the interlayer alkaline or alkaline earth cations [2,73] by the most common Al-Keggin ions $\left(\mathrm{Al}_{13}\right)$, represented as $\left[\mathrm{AlO}_{4} \mathrm{Al}_{12}(\mathrm{OH})_{24}\left(\mathrm{H}_{2} \mathrm{O}\right)_{12}\right]^{7+}[69,73]$ or $\left[\mathrm{Al}_{13} \mathrm{O}_{4}(\mathrm{OH})_{24}\left(\mathrm{H}_{2} \mathrm{O}\right)_{12}\right]^{7+}$ [74]. Parameters such as the $[\mathrm{OH}]:\left[\mathrm{Al}^{3+}\right]$ ratio, the $\left[\mathrm{Al}^{3+}\right]$ to clay mineral proportion and the aging temperature have a marked influence on the materials' stability and efficiency [75]. Not only $\mathrm{Al}^{3+}$ has been employed in the pillarization, but also other cations, such as $\mathrm{Fe}^{3+}[2,17,72,74,76-80]$, $\mathrm{Ti}^{4+}[76,81,82], \mathrm{Zr}^{4+}[73,83], \mathrm{Co}^{2+}, \mathrm{Ni}^{2+}$ and $\mathrm{Cu}^{2+}$ [84], and $\mathrm{Cu}^{2+}$ [85]. These works describe the preparation, characterization, and applications for the adsorption or degradation of different organic compounds since they can support catalysts for photodegradation. Excellent reviews addressed the theory and the preparation procedures $[68,75]$ as well as the removal of organic pollutants from wastewater [68]. The intercalation and pillarization processes 
produced adsorbent materials for different organic pollutants $[2,70,73,85-89]$ and catalysts or photocatalysts for pollutants degradation/mineralization $[69,72,74,82,90]$. Among the main applications, the use as adsorbents for pesticides, aiming for water treatment or the preparation of controlled release formulations, deserve highlighting.

\section{Adsorption of Pesticides by Intercalated and Pillared Clay Minerals}

Matthes and Kahr (2000) prepared Al- and Zr-intercalated and pillared bentonites (Bt) [73]. These sorbents were employed to adsorb organic 3-chloroaniline (3-CA), atrazine (AT), and 3-chlorophenol acid (3-CP), using the batch approach. No kinetic studies were undertaken, measuring the adsorption isotherms after an overnight shaking period. The dispersions (200 $\mathrm{mg}$ in $10.0 \mathrm{~mL}$ ) were centrifuged, and the remaining concentration of each compound was quantified in the supernatant using UV-Vis spectrophotometry. No discussion addressed eventual matrix interferences requiring chromatographic separations before the quantifications of the adsorbates. The fresh adsorbents were compared to the aged ones, which were kept under conditions of pressure and expansion at $60^{\circ} \mathrm{C}$ in artificial saline leachate for four months. The linearized Freundlich and Langmuir models were used to evaluate the adsorption characteristics (Table 5). The aged adsorbents exhibited a decrease in the $\mathrm{d}(001)$ basal spacing, BET surface areas, and micropore volumes because of the partial collapse of the intercalate polyhydroxy cations and pillars. All the modified adsorbents presented higher efficiency in comparison with the starting Bt. The Zr-pillared Bt performed better than the Al-pillared Bt. The pillared forms presented higher adsorption capacities than their intercalated counterparts and were similar to a commercial Al-pillared Bt. Concerning the adsorption of 3-CA, the Freundlich isotherms indicated low affinity of untreated $\mathrm{Bt}$, medium affinity of $\mathrm{Al}$ - and $\mathrm{Zr}$-intercalated $\mathrm{Bt}$, and high affinity for the pillared Bt. For AT, both fresh and aged sorbents pillared forms removed $92-100 \%$ from ultrapure water and artificial ionic leachate. Removal of 3-CA was between 14 and 100\%, whereas for $3-\mathrm{CP}$ was between $10 \%$ and $30 \%$. In these cases, competitive salt effects in higher ionic strength explained the low removal. The AT adsorption capacities from ultrapure water, determined by the linearized Langmuir model, were 129.9, 117.6, and $67.1 \mu \mathrm{mol} \mathrm{g}{ }^{-1}$ on the activated carbon, $\mathrm{Zr}-$, and $\mathrm{Al}$-pillared $\mathrm{Bt}$, respectively. In the presence of saline leachate, the adsorption capacities were 119.0, 35.3, and $32.9 \mu \mathrm{mol} \mathrm{g}^{-1}$, respectively, confirming the competitive effect of the ionic strength. These results suggest that intercalated and pillared Bt with high acidity could efficiently remove other organic bases. They could also remove the acidic compounds but to a lesser extension.

The clay minerals montmorillonite $(\mathrm{Mt})(\mathrm{K} 10$, from Aldrich) and vermiculite (Vt) were intercalated with $\mathrm{Fe}^{3+}$ polyhydroxy cations, and the adsorption behavior of the modified materials was compared with that of unmodified homoionic $\left(\mathrm{K}^{+}\right)$counterparts to adsorb AT and its main degradation products DEA, DIA, and HAT [2]. The intercalated suspensions were prepared using $[\mathrm{OH}]:\left[\mathrm{Fe}^{3+}\right]$ ratios between $0.75: 1$ and 2:1. Thirty $\mathrm{mg}$ of the adsorbents was equilibrated with mixed triazine solutions $(3.00 \mathrm{~mL})$ between 0.050 and $1.00 \mathrm{mg} \mathrm{L}^{-1}(140 \mathrm{rpm}, 24 \mathrm{~h}$ of contact time, an arbitrary choice because no kinetic study proved that equilibrium had been reached). After centrifuging the dispersion, the free concentrations were determined by HPLC-UV because strong matrix effects interfered in the direct UV-absorbance of supernatants even in the absence of the triazines. This work evaluated the desorption in ultrapure water (24 h at $140 \mathrm{rpm}$ ). Intercalation increased the $K_{\mathrm{F}}$ values for AT, DIA, and DEA. The $K_{F}$ for AT adsorption onto $\mathrm{KVt}$ increased from $10.5 \pm 0.7$ to $83 \pm 4 \mu \mathrm{mol}^{1-1 / n} \mathrm{~L}^{1 / n} \mathrm{~kg}^{-1}$ in the intercalated material prepared with $0.75: 1$ $\left[\mathrm{OH}^{-}\right]:\left[\mathrm{Fe}^{3+}\right]\left(R^{2}>0.99\right) . \mathrm{KVt}$ removed only about $10 \%$ of AT, whereas the intercalated materials adsorbed between 75 and $33 \%$ of the initial AT concentration $\left(1.0 \mathrm{mg} \mathrm{L}^{-1}\right)$. The $1 / n$ parameter decreased from 0.90 (AT in $\mathrm{KVt}$ ) to $0.54-0.63$, thus indicating a higher affinity and adsorbent heterogeneity of the intercalated solids. The DEA and DIA behavior was similar to AT, and the removal order was DIA $>\mathrm{AT}>>\mathrm{DEA}$. The materials adsorbed more than $90 \%$ of HAT, with the highest adsorption percentage observed for the unmodified KVt (about 97\%). This effect probably was due to the easy protonation of HAT (pKa 5.15) in 
comparison with the other compounds $(\mathrm{p} K \mathrm{a}<2)$, facilitating the retention by electrostatic interactions in addition to the prevailing hydrogen bonds that control the adsorption of the other molecules. Desorption of HAT from all the sorbents was $<3 \%$, confirming the strong affinity of this compound by the solids. The desorption $K_{F}$ values for HAT were higher than those measured for AT and DIA, whereas, for DEA, the desorption was not studied due to its low adsorption. An important finding was that the AT adsorption was similar to untreated $\mathrm{KVt}$ and intercalated $\mathrm{Vt}$ at the low $\mathrm{pH}$ values, suggesting the electrostatic mechanism between the herbicide and the Vt surfaces.

Montmorillonite and its intercalated forms adsorbed triazines (AT, HAT, and DIA) to concentrations less than the limit of detection of the HPLC-UV method. These results indicate a strong affinity between the triazine and Mt materials and an unsuitable experimental design. The mass to volume ratio used for Vt could not be, in principle, adopted for $\mathrm{Mt}$, so that such a ratio should have been studied in more detail to enable the construction of adsorption isotherms. For DEA, the adsorption was $>94 \%$ in the intercalated $\mathrm{Mt}$ and between 72 and $64 \%$ in the unmodified KMt. This effect seems to be related to the high specific surface area of Mt sorbents $\left(228-270 \mathrm{~m}^{2} \mathrm{~g}^{-1}\right)$ and lower charge density in comparison to Vt sorbents (31.4-52.1 $\left.\mathrm{m}^{2} \mathrm{~g}^{-1}\right)$, providing greater availability of interaction sites and suggesting the triazine adsorption as neutral molecules via hydrogen bonding and van der Waals forces. The negligible desorption suggested strong hydrogen bonds between the compounds and the polarized water molecules coordinated with $\mathrm{Fe}^{3+}$. The results proved that $\mathrm{Mt}$ is an efficient adsorbent for triazines, even in the unmodified form, at least for the K10 material from Aldrich. In another work, Abate and Masini (2007) [17] evaluated the same intercalated Fe-Vt, using a thermal treatment to obtain the pillared forms, treated at 250 and $400{ }^{\circ} \mathrm{C}$ for removal of AT. A significant adsorption enhancement was observed, with removal between $62.8 \%$ and $99.1 \%$ for the best calcination condition $\left(400{ }^{\circ} \mathrm{C}\right)$ and a low degree of desorption, demonstrating the Fe-pillared Vt as an efficient adsorbent of AT.

Intercalated and pillared clay minerals afford acidic sites, high specific surface areas, and porosity. Even so, these characteristics are often not enough for the adsorption of more hydrophobic compounds. Functionalization of intercalated or pillared clay minerals with organic cations produces adsorbents with enhanced adsorption towards hydrophobic organic compounds [91]. Bouras et al. (2007) [76] intercalated Mt using Al(III), Fe(III), and $\mathrm{Ti}(\mathrm{IV})$ and the resulting solids were treated using cetyltrimethylammonium bromide (CTAB) aiming at the adsorption of diuron (herbicide) and the degradation products 3 (3,4-dichlorophenyl)-1-methyl urea (DCPMU), 1-(3,4-dichlorophenyl) urea (DCPU), and 2,4-dichloroaniline (DCA). The authors used a Bt sample saturated with $\mathrm{Na}^{+}$to produce the intercalated forms, and the particles $<2 \mu \mathrm{m}$ were treated with CTAB, using 4,5 , and $10 \mathrm{mmol} \mathrm{g}^{-1}$ of $\mathrm{CTAB} /$ solids ratios for $\mathrm{Al}$, Fe, and Ti forms, respectively. A $250 \mu \mathrm{g} \mathrm{L}^{-1}$ solution $(100 \mathrm{~mL})$ was equilibrated with 5 to $80 \mathrm{mg}$ of the sorbents $\left(250 \mathrm{rpm}, 24 \mathrm{~h}, 18-20{ }^{\circ} \mathrm{C}\right)$ at $\mathrm{pH} 3$ or 6 . The solid phases were separated, and the compounds' concentration was determined by UV-liquid chromatography. For diuron at $\mathrm{pH}$ 6, the intercalated Al-Mt adsorbed near $300 \mu \mathrm{g} \mathrm{g}^{-1}$, whereas the organophilic counterpart adsorbed about $600 \mu \mathrm{g} \mathrm{g}^{-1}$, confirming the key role of CTAB in enhancing the adsorption. The higher adsorption of diuron compared to its degradation products was attributed to the higher molar mass and lower water solubility of the parent herbicide. The adsorption isotherms exhibited a cooperative effect in which the adsorbed molecules enhanced the affinity of the adsorbent toward the adsorbates as the loaded adsorbate concentration increased, not reaching a saturation plateau. Such data are not usually fitted by the Freundlich isotherm, but rather by the combined Freundlich-Langmuir equation (Equation (9)). Although the authors show some $R^{2}$ values $>0.95$, some fittings resulted in $R^{2}<0.90$, indicating the Freundlich equation is not suitable for describing all compounds' adsorption. The efficiency of the organophilic materials was higher to Mt modified with Ti(IV), followed by Fe(III) and $\mathrm{Al}(\mathrm{III})$, and the results suggest the applicability of the sorbents in the removal of organic compounds in industrial effluents in acidic media. 
Table 5. Sorbent characterizations and sorption features of pesticides and metabolites onto intercalated or pillared clay minerals.

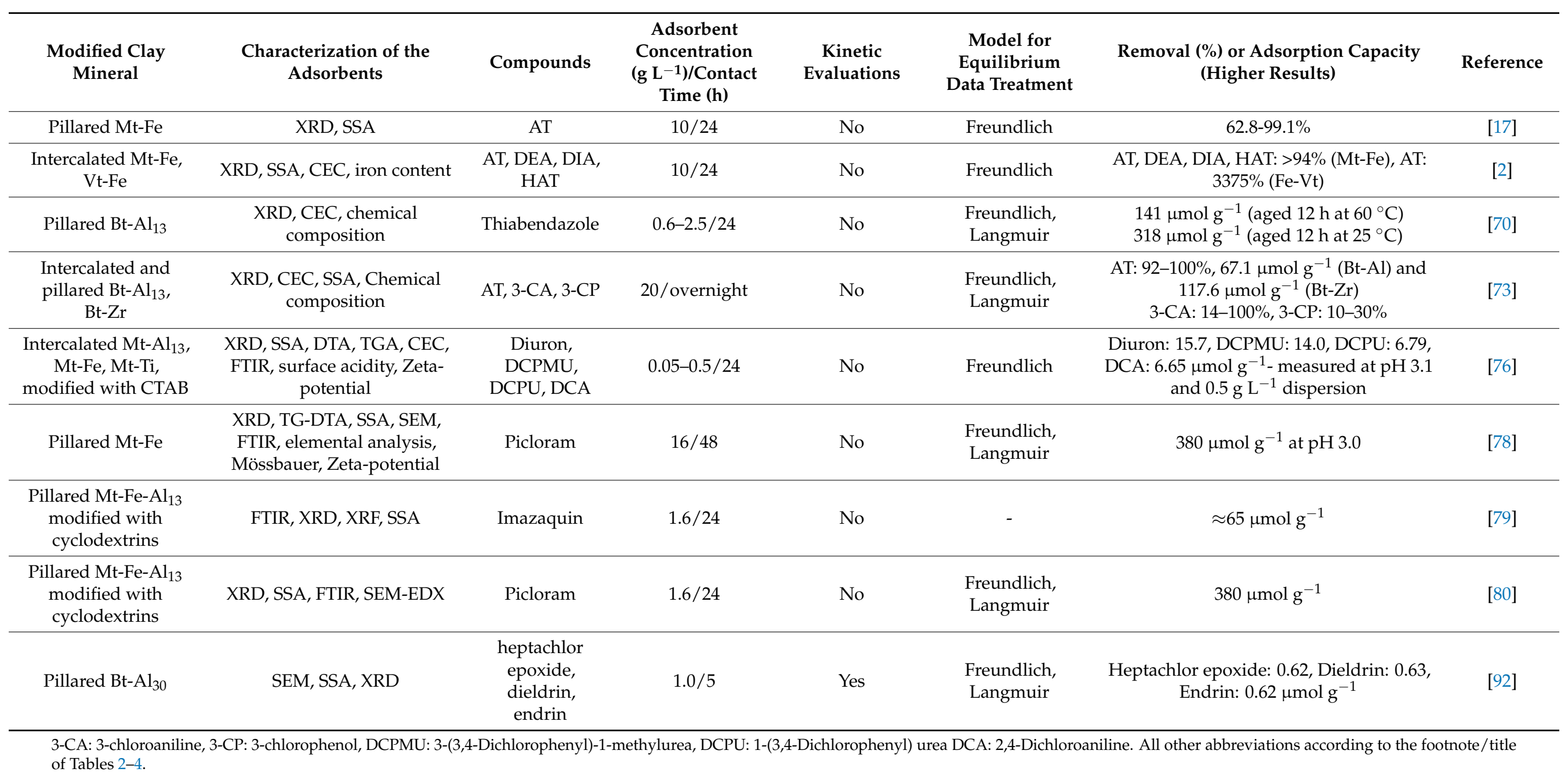


Marco-Brown et al. (2012) [78] investigated the adsorption of the anionic herbicide picloram on iron oxide-pillared Mt. The pillaring solution was prepared in a ratio of $\left[\mathrm{OH}^{-}\right] /[\mathrm{Fe}]=2$ and kept under stirring for $4 \mathrm{~h}$ (aging time). A $1 \mathrm{wt} \%$ suspension of $\mathrm{Mt}$ was dispersed in the pillaring solution at $60 \mathrm{mmol}$ of Fe to one gram of Mt ratio. After $12 \mathrm{~h}$ of stirring, the solid phase was separated, washed, and heated at $300^{\circ} \mathrm{C}$ for $2 \mathrm{~h}$. The adsorption properties towards picloram were investigated, using a $16 \mathrm{~g} \mathrm{~L}^{-1}$ dispersion in $1 \mathrm{mmol} \mathrm{L}^{-1} \mathrm{KCl}$, at $\mathrm{pH} 3,5$, and 7 , at $25^{\circ} \mathrm{C}$, for $48 \mathrm{~h}$ (another choice without the support of kinetic data). After centrifugation and filtration, the supernatants were analyzed by ion chromatography. Both the nonlinear regression analysis of the Langmuir and the linearized Freundlich models presented $R^{2}$ values $>0.95$, and the adsorption capacity of picloram increased from $0.30 \mathrm{mmol} \mathrm{g}^{-1}$ (pH 7) to $0.38 \mathrm{mmol} \mathrm{g}^{-1}$ (pH 3), being this behavior characteristic of anionic species. At $\mathrm{pH} 3$, the amount adsorbed by the raw $\mathrm{Mt}$ was $0.14 \mathrm{mmol} \mathrm{g}^{-1}$, a capacity of about $50 \%$ of that pillared Mt (Table 5). The $K_{L}$ (Langmuir) and $K_{F}$ (Freundlich) constants confirmed the affinity order. Coordination of the pyridinic nitrogen atom and the $\mathrm{COO}^{-}$groups with $\mathrm{Fe}(\mathrm{III})$ explained the increased adsorption. The pillared materials could be employed for remediation purposes or to produce materials aiming at the controlled release of herbicides.

Roca Jalil et al. (2013) [70] prepared two Al-pillared bentonites using 20 meq of $\mathrm{Al}$ per gram of bentonite and calcined the product at $500{ }^{\circ} \mathrm{C}$ aiming to adsorb the fungicide thiabendazole. The adsorption properties were investigated employing the batch approach and $24 \mathrm{~h}$ of the contact time. After centrifugation, the thiabendazole concentrations were determined by UV-vis spectrophotometry. Freundlich and Langmuir fitted the data with $R^{2}>0.97$. Curiously, the Freundlich equation was linearized, whereas the Langmuir equation was used in the nonlinear form. The maximum adsorption capacity of the natural clay mineral was $11.91 \mathrm{mg} \mathrm{g}^{-1}$, whereas 28.38 and $63.87 \mathrm{mg} \mathrm{g}^{-1}$ were determined for the two pillared clays (at $\mathrm{pH}$ 6.0). Compared to the unmodified bentonite, the enhanced adsorption capacity of the pillared forms was explained by their enhanced microporosity and hydrophobicity and lower $\mathrm{pH}_{\mathrm{PZC}}$ (about 6.0 for the unmodified bentonite and around 4.8-5.0 for the pillared ones). A net negative charge prevails in the pillared forms at $\mathrm{pH} 6.0$, favoring the electrostatic interactions with the small fraction of cationic thiabendazole (pKa 4.64). In another study, Roca Jalil et al. (2014) [88] employed similar conditions to demonstrate the influence of the $\mathrm{Al}$ ratio in the pillarization using 5, 10, 15, and 20 meq of Al per gram of bentonite. Freundlich, Langmuir, and Sips fitted the adsorption revealing that 10 meq of Al per gram of clay mineral was the best ratio to maximize adsorption.

Aiming for the controlled release of the herbicide picloram, Marco-Brown et al. (2017) [80] proposed a formulation using Fe-Al-pillared montmorillonite, using the ratio for $\mathrm{Fe} /(\mathrm{Fe}+\mathrm{Al})$ of 0.15 and 0.50 . The authors employed cyclodextrins, which increased up to 2.5 times the solubility of picloram, owing to the presence of inclusion complexes [7]. The adsorption isotherms were measured using $24 \mathrm{mg}$ of the pillared materials, dispersed in $15 \mathrm{~mL}$ of up to $1.66 \mathrm{mmol} \mathrm{L}^{-1}$ picloram for $24 \mathrm{~h}$ at $20^{\circ} \mathrm{C}$. After centrifugation, the concentration of picloram was determined in the aqueous phases using liquid chromatography. The Langmuir model fitted the data and showed higher adsorption for $\mathrm{Fe} /(\mathrm{Fe}+$ $\mathrm{Al})=0.5$ (up to $0.38 \mathrm{~mol} \mathrm{~kg}^{-1}$ ) compared to 0.15 ratio $\left(0.19 \mathrm{~mol} \mathrm{~kg}^{-1}\right)$. Although the cyclodextrins increased the solubility of the herbicide, the interaction mechanism of picloram with pillared clay minerals was not modified, as evidenced by the similar $K_{\mathrm{L}}$ values. FTIR characterization also indicated the interaction between carboxylic and pyridinic groups with the clay surfaces in the presence or absence of cyclodextrins, in agreement with the similar magnitude of the $K_{\mathrm{L}}$ for the two adsorbents. A sandy soil sample was employed to evaluate the releasing of picloram using the pillared mineral at the best ratio $(\mathrm{Fe} /(\mathrm{Fe}$ $+\mathrm{Al})=0.5)$, treated or untreated with cyclodextrin, in comparison with the commercial formulation. The results demonstrated that 13 irrigation steps released about $97 \%$ picloram from the commercial formulation, whereas the Fe-Al pillared sorbents reduced picloram releasing to about 22 to $28 \%$. 
In addition to the conventional $\mathrm{Al}-\mathrm{Keggin}$ ions $\left(\mathrm{Al}_{13}\right)$, another pillaring agent is the structure $\left[\mathrm{Al}_{30} \mathrm{O}_{8}(\mathrm{OH})_{56}\left(\mathrm{H}_{2} \mathrm{O}\right)_{24}\right]^{18+}$ denoted as $\mathrm{Al}_{30}$, recently reviewed by [75] to modify Mt. Using Keggin ion, Farghali et al. [92] proposed the production of pillared $\mathrm{Al}_{30}-\mathrm{BT}$ $\left(300{ }^{\circ} \mathrm{C}\right)$, aiming to remove the chlorinated pesticides heptachlor epoxide, dieldrin, and endrin, from aqueous medium. Dispersions prepared in $25 \mathrm{~mL}$ of $0.2 \mathrm{mg} \mathrm{L}^{-1}$ of each pesticide were used to investigate the adsorption kinetics in a $0.5-20 \mathrm{~h}$ time interval, the $\mathrm{pH}$ effect in a 3-10 range, and temperatures between 25 and $50{ }^{\circ} \mathrm{C}$. The filtered supernatants were extracted and analyzed by gas chromatography-mass spectrometry. The best adsorption conditions were at $\mathrm{pH} 7.5,5 \mathrm{~h}$ of contact time, $25 \mathrm{mg}$ of adsorbent, and $45^{\circ} \mathrm{C}$. The linearized pseudo-first-order best fitted the kinetic data, as suggested by the higher $R^{2}$ values. The best agreement between the experimental and calculated $q_{\mathrm{e}}$ values also confirmed that the adsorption followed pseudo-first-order kinetics. Linearized Langmuir and Freundlich equations fitted the adsorption isotherms. The Freundlich equation fitted the data with $0.989>R^{2}>0.986$, a correlation slightly better than that found by the linearized Langmuir model $\left(0.972>R^{2}>0.962\right)$. A closer look at the linearized Langmuir graph $\left(c_{e} / q_{e}\right.$ vs. $\left.c_{e}\right)$ shows two linear portions, suggesting more than one kind of adsorption site. However, the $1 / n$ values from the Freundlich equation between 2.09 and 2.18 suggest cooperative adsorption. Nevertheless, this statement must be considered carefully since the isotherms were L-shaped and not S-shaped, as most cooperative adsorption. Besides, if the process was cooperative, the Langmuir equation would not fit the data at all. Unfortunately, the adsorption on the unmodified starting bentonite was not measured, so that it is not possible to evaluate the pillaring effect.

\section{Concluding Remarks}

The use of raw or modified clay minerals for elaborating sorbents to environmental cleanup and reducing pesticide spills' impacts continues to increase. Additionally to the impressive availability of image and analytical techniques for materials characterization and understanding the interaction mechanisms, the design of adsorbents and adsorptionbased treatments still relies on kinetic and equilibrium experiments. This review proposed some guidelines for the adsorption experiments and commented on some of the published results. In summary, the analytical technique to measure the free concentrations must be selective and sensitive, having a wide linear dynamic range to enable reliable measurements under low and high degrees of site occupation. The adsorbent mass to solution ratio and the sensitivity of the analytical technique are parameters to consider aiming to obtain reliable measurements of free concentrations in a wide range of site occupations. Kinetic measurements should precede the construction of adsorption isotherms and thermodynamic experiments since both of them require measurements under equilibrium conditions. The availability of software packages favors the fitting of kinetic and adsorption isotherms by nonlinear regression analysis, thus minimizing the errors inherent to the linearization.

In many cases, the comparison of adsorption constants and capacities does not consider the standard deviations of these parameters, thus making the comparison subjective and without statistical support. Finally, the experimental conditions should emulate as much as possible those found in the environment. Thus, the influence of ionic strength, $\mathrm{pH}$, temperature, and natural organic matter, among others, on the adsorption parameters should be evaluated for each new clay mineral-based adsorbent proposed.

Author Contributions: Conceptualization, J.C.M. and G.A., writing-original draft, J.C.M. and G.A., writing-review and editing, J.C.M. and G.A. All authors have read and agreed to the published version of the manuscript.

Funding: National Council for Scientific and Technological Development (CNPq) project \# 303940/ 2017-4.

Data Availability Statement: Data sharing is not applicable to this review article.

Acknowledgments: J.C.M. acknowledges National Council for Scientific and Technological Development (CNPq) project \# 303940/2017-4. 
Conflicts of Interest: The authors declare no conflict of interest.

\section{References}

1. Pimentel, D. Green revolution agriculture and chemical hazards. Sci. Total Environ. 1996, 188, S86-S98. [CrossRef]

2. Abate, G.; Masini, J.C. Adsorption of atrazine, hydroxyatrazine, deethylatrazine, and deisopropylatrazine onto Fe(III) polyhydroxy cations intercalated vermiculite and montmorillonite. J. Agric. Food Chem. 2005, 53, 1612-1619. [CrossRef] [PubMed]

3. Horak, I.; Horn, S.; Pieters, R. Agrochemicals in freshwater systems and their potential as endocrine disrupting chemicals: A South African context. Environ. Pollut. 2021, 268, 115718. [CrossRef] [PubMed]

4. Kaushal, J.; Khatri, M.; Arya, S.K. A treatise on Organophosphate pesticide pollution: Current strategies and advancements in their environmental degradation and elimination. Ecotoxicol. Environ. Saf. 2021, 207, 111483. [CrossRef] [PubMed]

5. Chow, R.; Scheidegger, R.; Doppler, T.; Dietzel, A.; Fenicia, F.; Stamm, C. A review of long-term pesticide monitoring studies to assess surface water quality trends. Water Res. X 2020, 9, 100064. [CrossRef]

6. Rigobello-Masini, M.; Pereira, E.A.O.; Abate, G.; Masini, J.C. Solid-Phase Extraction of Glyphosate in the Analyses of Environmental, Plant, and Food Samples. Chromatographia 2019, 82, 1121-1138. [CrossRef]

7. Undabeytia, T.; Shuali, U.; Nir, S.; Rubin, B. Applications of chemically modified clay minerals and clays to water purification and slow release formulations of herbicides. Minerals 2021, 11, 9. [CrossRef]

8. Natarelli, C.V.L.; Claro, P.I.C.; Miranda, K.W.E.; Ferreira, G.M.D.; de Oliveira, J.E.; Marconcini, J.M. 2,4-Dichlorophenoxyacetic acid adsorption on montmorillonite organoclay for controlled release applications. SN Appl. Sci. 2019, 1, 1-13. [CrossRef]

9. Awad, A.M.; Shaikh, S.M.R.; Jalab, R.; Gulied, M.H.; Nasser, M.S.; Benamor, A.; Adham, S. Adsorption of organic pollutants by natural and modified clays: A comprehensive review. Sep. Purif. Technol. 2019, 228, 115719. [CrossRef]

10. Lelario, F.; Gardi, I.; Mishael, Y.; Dolev, N.; Undabeytia, T.; Nir, S.; Scrano, L.; Bufo, S.A. Pairing micropollutants and claycomposite sorbents for efficient water treatment: Filtration and modeling at a pilot scale. Appl. Clay Sci. 2017, 137, 225-232. [CrossRef]

11. Shabeer, T.P.A.; Saha, A.; Gajbhiye, V.T.; Gupta, S.; Manjaiah, K.M.; Varghese, E. Simultaneous removal of multiple pesticides from water: Effect of organically modified clays as coagulant aid and adsorbent in coagulation-flocculation process. Environ. Technol. 2014, 35, 2619-2627. [CrossRef]

12. Amari, A.; Alzahrani, F.M.; Katubi, K.M.; Alsaiari, N.S.; Tahoon, M.A.; Rebah, F. Ben Clay-polymer nanocomposites: Preparations and utilization for pollutants removal. Materials 2021, 14, 1365. [CrossRef]

13. Infante, C.M.C.; Masini, J.C. Development of a spectrophotometric sequential injection methodology for online monitoring of the adsorption of paraquat on clay mineral and soil. Spectrosc. Lett. 2007, 40, 3-14. [CrossRef]

14. Guégan, R. Organoclay applications and limits in the environment. C. R. Chim. 2019, 22, 132-141. [CrossRef]

15. Mdlalose, L.; Balogun, M.; Setshedi, K.; Chimuka, L.; Chetty, A. Adsorption of phosphates using transition metals-modified bentonite clay. Sep. Sci. Technol. 2019, 54, 2397-2408. [CrossRef]

16. Almasri, D.A.; Rhadfi, T.; Atieh, M.A.; McKay, G.; Ahzi, S. High performance hydroxyiron modified montmorillonite nanoclay adsorbent for arsenite removal. Chem. Eng. J. 2018, 335, 1-12. [CrossRef]

17. Abate, G.; Masini, J.C. Influence of thermal treatment applied to Fe(III) polyhydroxy cation intercalated vermiculite on the adsorption of atrazine. J. Agric. Food Chem. 2007, 55, 3555-3560. [CrossRef]

18. Khalaf, H.; Bouras, O.; Perrichon, V. Synthesis and characterization of Al-pillared and cationic surfactant modified Al-pillared Algerian bentonite. Microporous Mater. 1997, 8, 141-150. [CrossRef]

19. Lenoble, V.; Bouras, O.; Deluchat, V.; Serpaud, B.; Bollinger, J.C. Arsenic adsorption onto pillared clays and iron oxides. J. Colloid Interface Sci. 2002, 255, 52-58. [CrossRef]

20. do Nascimento, F.H.; de Souza Costa, D.M.; Masini, J.C. Evaluation of thiol-modified vermiculite for removal of $\mathrm{Hg}$ (II) from aqueous solutions. Appl. Clay Sci. 2016, 124-125, 227-235. [CrossRef]

21. Abate, G.; Masini, J.C. Sorption of atrazine, propazine, deethylatrazine, deisopropylatrazine and hydroxyatrazine onto organovermiculite. J. Braz. Chem. Soc. 2005, 16, 936-943. [CrossRef]

22. Uddin, M.K. A review on the adsorption of heavy metals by clay minerals, with special focus on the past decade. Chem. Eng. J. 2017, 308, 438-462. [CrossRef]

23. Adewuyi, A.; Oderinde, R.A. Chemically modified vermiculite clay: A means to remove emerging contaminant from polluted water system in developing nation. Polym. Bull. 2019, 76, 4967-4989. [CrossRef]

24. Leite, S.T.; do Nascimento, F.H.; Masini, J.C. Fe(III)-polyhydroxy cations supported onto K10 montmorillonite for removal of phosphate from waters. Heliyon 2020, 6, e03868. [CrossRef]

25. Zarpon, L.; Abate, G.; do Santos, L.B.O.; Masini, J.C. Montmorillonite as an adsorbent for extraction and concentration of atrazine, propazine, deethylatrazine, deisopropylatrazine and hydroxyatrazine. Anal. Chim. Acta 2006, 579, 81-87. [CrossRef]

26. Manzotti, F.; dos Santos, O.A.A. Evaluation of removal and adsorption of different herbicides on commercial organophilic clay. Chem. Eng. Commun. 2019, 206, 1526-1543. [CrossRef]

27. Organization for Economic Cooperation and Development/OCDE. 106 OECD Guideline for the Testing of Chemicals. AdsorptionDesorption Using Batch Equilibrium Method; OCDE: Paris, France, 2000; pp. 1-44.

28. Tran, H.N.; You, S.J.; Hosseini-Bandegharaei, A.; Chao, H.P. Mistakes and inconsistencies regarding adsorption of contaminants from aqueous solutions: A critical review. Water Res. 2017, 120, 88-116. [CrossRef] [PubMed] 
29. Lagergren, S.K. About the theory of so-called adsorption of soluble substances. Sven. Vetensk. Handl. 1898, $24,1-39$.

30. Ho, Y.S.; McKay, G. A Comparison of chemisorption kinetic models applied to pollutant removal on various sorbents. Process Saf. Environ. Prot. 1998, 76, 332-340. [CrossRef]

31. Abate, G.; Dos Santos, L.B.O.; Colombo, S.M.; Masini, J.C. Sequential injection analysis as a tool for on-line monitoring the sorption of fulvic acid onto modified vermiculite. J. Braz. Chem. Soc. 2006, 17, 491-496. [CrossRef]

32. Blanchard, G.; Maunaye, M.; Martin, G. Removal of heavy metals from waters by means of natural zeolites. Water Res. 1984, 18, 1501-1507. [CrossRef]

33. Moussout, H.; Ahlafi, H.; Aazza, M.; Maghat, H. Critical of linear and nonlinear equations of pseudo-first order and pseudosecond order kinetic models. Karbala Int. J. Mod. Sci. 2018, 4, 244-254. [CrossRef]

34. Tran, H.N.; You, S.J.; Chao, H.P. Thermodynamic parameters of cadmium adsorption onto orange peel calculated from various methods: A comparison study. J. Environ. Chem. Eng. 2016, 4, 2671-2682. [CrossRef]

35. Lima, É.C.; Adebayo, M.A.; Machado, F.M.; Bergmann, C.P.; Machado, F.M. (Eds.) Carbon Nanostructures as Adsorbents for Environmental and Biological Applications; Springer: Cham, Switzerland, 2015; pp. 33-69.

36. Weber, W.J.; Morris, J.C. Kinetics of Adsorption on Carbon from Solutions. J. Sanit. Eng. Div. 1963, 89, 31-39. [CrossRef]

37. Bolster, C.H.; Hornberger, G.M. On the Use of Linearized Langmuir Equations. Soil Sci. Soc. Am. J. 2007, 71, 1796-1806. [CrossRef]

38. Langmuir, I. The adsorption of gases on plane surfaces of glass, mica and patinum. J. Am. Chem. Soc. 1918, 40, 1361-1403. [CrossRef]

39. Sposito, G. Derivation of the Freundlich equation for ion exchange reaction in soils. Soil Sci. Soc. Am. J. 1980, 44, 652-654. [CrossRef]

40. Hall, K.R.; Eagleton, L.C.; Acrivos, A.; Vermeulen, T. Pore- and solid-diffusion kinetics in fixed-bed adsorption under constantpattern conditions. Ind. Eng. Chem. Fundam. 1966, 5, 212-223. [CrossRef]

41. Milonjić, S.K. A consideration of the correct calculation of thermodynamic parameters of adsorption. J. Serbian Chem. Soc. 2007, 72, 1363-1367. [CrossRef]

42. Zhou, X.; Zhou, X. The Unit Problem in the Thermodynamic Calculation of Adsorption Using the Langmuir Equation. Chem. Eng. Commun. 2014, 201, 1459-1467. [CrossRef]

43. Worch, E. Adsorption Technology in Water Treatment; De Gruyter: Berlin, Germany, 2021; pp. 49-88.

44. Otalvaro, J.O.; Brigante, M. Interaction of pesticides with natural and synthetic solids. Evaluation in dynamic and equilibrium conditions. Environ. Sci. Pollut. Res. 2018, 25, 6707-6719. [CrossRef]

45. Azejjel, H.; del Hoyo, C.; Draoui, K.; Rodríguez-Cruz, M.S.; Sánchez-Martín, M.J. Natural and modified clays from Morocco as sorbents of ionizable herbicides in aqueous medium. Desalination 2009, 249, 1151-1158. [CrossRef]

46. Ait Sidhoum, D.; Socías-Viciana, M.M.; Ureña-Amate, M.D.; Derdour, A.; González-Pradas, E.; Debbagh-Boutarbouch, N. Removal of paraquat from water by an Algerian bentonite. Appl. Clay Sci. 2013, 83-84, 441-448. [CrossRef]

47. Pateiro-Moure, M.; Nóvoa-Muñoz, J.C.; Arias-Estévez, M.; López-Periago, E.; Martínez-Carballo, E.; Simal-Gándara, J. Quaternary herbicides retention by the amendment of acid soils with a bentonite-based waste from wineries. J. Hazard. Mater. 2009, 164, 769-775. [CrossRef]

48. Etcheverry, M.; Cappa, V.; Trelles, J.; Zanini, G. Montmorillonite-alginate beads: Natural mineral and biopolymers based sorbent of paraquat herbicides. J. Environ. Chem. Eng. 2017, 5, 5868-5875. [CrossRef]

49. Wang, M.; Orr, A.A.; He, S.; Dalaijamts, C.; Chiu, W.A.; Tamamis, P.; Phillips, T.D. Montmorillonites Can Tightly Bind Glyphosate and Paraquat Reducing Toxin Exposures and Toxicity. ACS Omega 2019, 4, 17702-17713. [CrossRef] [PubMed]

50. Seki, Y.; Yurdakoç, K. Paraquat adsorption onto clays and organoclays from aqueous solution. J. Colloid Interface Sci. 2005, 287, 1-5. [CrossRef]

51. Shattar, S.F.A.; Zakaria, N.A.; Foo, K.Y. Acid modified natural clay as a judicious solution for the successive treatment of ametryn. Desalin. Water Treat. 2018, 103, 270-279. [CrossRef]

52. Shattar, S.F.A.; Zakaria, N.A.; Foo, K.Y. Utilization of montmorillonite as a refining solution for the treatment of ametryn, a second generation of pesticide. J. Environ. Chem. Eng. 2017, 5, 3235-3242. [CrossRef]

53. Shattar, S.F.A.; Zakaria, N.A.; Foo, K.Y.; Undabeytia, T.; Shuali, U.; Nir, S.; Rubin, B.; Sartori, F.; Vidrio, E.; Pimentel, D. Green revolution agriculture and chemical hazards. Minerals 1996, 188, 479-517.

54. Bouazza, F.; Benguella, B.; Soussi, S. Elimination of pesticides by natural and modified clays. Can. J. Chem. 2018, 96, 975-983. [CrossRef]

55. Tarazona, J.V.; Court-Marques, D.; Tiramani, M.; Reich, H.; Pfeil, R.; Istace, F.; Crivellente, F. Glyphosate toxicity and carcinogenicity: A review of the scientific basis of the European Union assessment and its differences with IARC. Arch. Toxicol. 2017, 91, 2723-2743. [CrossRef]

56. Pereira, R.C.; da Costa, A.C.S.; Ivashita, F.F.; Paesano, A.; Zaia, D.A.M. Interaction between glyphosate and montmorillonite in the presence of artificial seawater. Heliyon 2020, 6, e03532. [CrossRef] [PubMed]

57. Khoury, G.A.; Gehris, T.C.; Tribe, L.; Torres Sánchez, R.M.; dos Santos Afonso, M. Glyphosate adsorption on montmorillonite: An experimental and theoretical study of surface complexes. Appl. Clay Sci. 2010, 50, 167-175. [CrossRef]

58. Do Nascimento, F.H.; Masini, J.C. Influence of humic acid on adsorption of $\mathrm{Hg}$ (II) by vermiculite. J. Environ. Manag. 2014, 143, 1-7. [CrossRef] 
59. Abate, G.; Masini, J.C. Influence of $\mathrm{pH}$ and ionic strength on removal processes of a sedimentary humic acid in a suspension of vermiculite. Colloids Surf. A Physicochem. Eng. Asp. 2003, 226, 25-34. [CrossRef]

60. Shattar, S.F.A.; Zakaria, N.A.; Foo, K.Y. Feasibility of montmorillonite-assisted adsorption process for the effective treatment of organo-pesticides. Desalin. Water Treat. 2016, 57, 13645-13677. [CrossRef]

61. Leovac, A.; Vasyukova, E.; Ivančev-Tumbas, I.; Uhl, W.; Kragulj, M.; Tričković, J.; Kerkez, D.; Dalmacija, B. Sorption of atrazine, alachlor and trifluralin from water onto different geosorbents. RSC Adv. 2015, 5, 8122-8133. [CrossRef]

62. Abate, G.; dos Santos, L.B.O.; Colombo, S.M.; Masini, J.C. Removal of fulvic acid from aqueous media by adsorption onto modified vermiculite. Appl. Clay Sci. 2006, 32, 261-270. [CrossRef]

63. Park, Y.; Sun, Z.; Ayoko, G.A.; Frost, R.L. Removal of herbicides from aqueous solutions by modified forms of montmorillonite. J. Colloid Interface Sci. 2014, 415, 127-132. [CrossRef]

64. Oiwa, M.; Yamaguchi, K.; Hayashi, H.; Saitoh, T. Rapid sorption of fenitrothion on didodecyldimethylammonium bromidemontmorillonite organoclay followed by the degradation into less toxic 3-methyl-4-nitrophenolate. J. Environ. Chem. Eng. 2020, 8, 104000. [CrossRef]

65. Giles, C.H.; Smith, D. A general treatment and classification of the solute adsorption isotherm I. Theoretical. J. Collooid Interface Sci. 1974, 47, 755-765. [CrossRef]

66. Saha, A.; Ahammed, S.T.; Gajbhiye, V.T.; Gupta, S.; Kumar, R. Removal of mixed pesticides from aqueous solutions using organoclays: Evaluation of equilibrium and kinetic model. Bull. Environ. Contam. Toxicol. 2013, 91, 111-116. [CrossRef] [PubMed]

67. Narayanan, N.; Gupta, S.; Gajbhiye, V.T.; Manjaiah, K.M. Optimization of isotherm models for pesticide sorption on biopolymernanoclay composite by error analysis. Chemosphere 2017, 173, 502-511. [CrossRef]

68. Najafi, H.; Farajfaed, S.; Zolgharnian, S.; Mosavi Mirak, S.H.; Asasian-Kolur, N.; Sharifian, S. A comprehensive study on modified-pillared clays as an adsorbent in wastewater treatment processes. Process Saf. Environ. Prot. 2021, 147, 8-36. [CrossRef]

69. Galeano, L.A.; Vicente, M.Á.; Gil, A. Catalytic degradation of organic pollutants in aqueous streams by mixed Al/M-pillared clays (M = Fe, Cu, Mn). Catal. Rev. Sci. Eng. 2014, 56, 239-287. [CrossRef]

70. Roca Jalil, M.E.; Vieira, R.S.; Azevedo, D.; Baschini, M.; Sapag, K. Improvement in the adsorption of thiabendazole by using aluminum pillared clays. Appl. Clay Sci. 2013, 71, 55-63. [CrossRef]

71. Biswas, B.; Warr, L.N.; Hilder, E.F.; Goswami, N.; Rahman, M.M.; Churchman, J.G.; Vasilev, K.; Pan, G.; Naidu, R. Biocompatible functionalisation of nanoclays for improved environmental remediation. Chem. Soc. Rev. 2019, 48, 3740-3770. [CrossRef]

72. Khankhasaeva, S.T.; Badmaeva, S.V. Removal of p-aminobenzenesulfanilamide from water solutions by catalytic photo-oxidation over Fe-pillared clay. Water Res. 2020, 185, 116212. [CrossRef]

73. Matthes, W.; Kahr, G. Sorption of organic compounds by Al and Zr-hydroxy intercalated and pillared bentonite. Clays Clay Miner. 2000, 48, 593-602. [CrossRef]

74. Herney-Ramirez, J.; Vicente, M.A.; Madeira, L.M. Heterogeneous photo-Fenton oxidation with pillared clay-based catalysts for wastewater treatment: A review. Appl. Catal. B Environ. 2010, 98, 10-26. [CrossRef]

75. Cardona, Y.; Korili, S.A.; Gil, A. Understanding the formation of Al13 and Al30 polycations to the development of microporous materials based on Al13-and Al30-PILC montmorillonites: A review. Appl. Clay Sci. 2021, 203, 105996. [CrossRef]

76. Bouras, O.; Bollinger, J.C.; Baudu, M.; Khalaf, H. Adsorption of diuron and its degradation products from aqueous solution by surfactant-modified pillared clays. Appl. Clay Sci. 2007, 37, 240-250. [CrossRef]

77. Li, J.; Li, Y.; Lu, J. Adsorption of herbicides 2,4-D and acetochlor on inorganic-organic bentonites. Appl. Clay Sci. 2009, 46, 314-318. [CrossRef]

78. Marco-Brown, J.L.; Barbosa-Lema, C.M.; Torres Sánchez, R.M.; Mercader, R.C.; dos Santos Afonso, M. Adsorption of picloram herbicide on iron oxide pillared montmorillonite. Appl. Clay Sci. 2012, 58, 25-33. [CrossRef]

79. Undabeytia, T.; Galán-Jiménez, M.C.; Gómez-Pantoja, E.; Vázquez, J.; Casal, B.; Bergaya, F.; Morillo, E. Fe-pillared clay mineralbased formulations of imazaquin for reduced leaching in soil. Appl. Clay Sci. 2013, 80-81, 382-389. [CrossRef]

80. Marco-Brown, J.L.; Undabeytia, T.; Torres Sánchez, R.M.; dos Santos Afonso, M. Slow-release formulations of the herbicide picloram by using Fe-Al pillared montmorillonite. Environ. Sci. Pollut. Res. 2017, 24, 10410-10420. [CrossRef]

81. Vercellone, S.Z.; Sham, E.; Torres, E.M.F. Measure of Zeta Potential of Titanium Pillared Clays. Proc. Mater. Sci. 2015, 8, 599-607. [CrossRef]

82. Abdennouri, M.; Baâlala, M.; Galadi, A.; El Makhfouk, M.; Bensitel, M.; Nohair, K.; Sadiq, M.; Boussaoud, A.; Barka, N. Photocatalytic degradation of pesticides by titanium dioxide and titanium pillared purified clays. Arab. J. Chem. 2016, 9, S313-S318. [CrossRef]

83. Gil, A.; Assis, F.C.C.; Albeniz, S.; Korili, S.A. Removal of dyes from wastewaters by adsorption on pillared clays. Chem. Eng. J. 2011, 168, 1032-1040. [CrossRef]

84. Cabrera-Lafaurie, W.A.; Román, F.R.; Hernández-Maldonado, A.J. Transition metal modified and partially calcined inorganicorganic pillared clays for the adsorption of salicylic acid, clofibric acid, carbamazepine, and caffeine from water. J. Colloid Interface Sci. 2012, 386, 381-391. [CrossRef]

85. Yan, F.; Spyrou, K.; Thomou, E.; Kumar, S.; Cao, H.; Stuart, M.C.A.; Pei, Y.; Gournis, D.; Rudolf, P. Smectite clay pillared with copper complexed polyhedral oligosilsesquioxane for adsorption of chloridazon and its metabolites. Environ. Sci. Nano 2020, 7 , 424-436. [CrossRef] 
86. Zielke, R.C.; Pinnavaia, T.J. Modified clays for the adsorption of environmental toxicants: Binding of chlorophenols to pillared, delaminated, and hydroxy-interlayered smectites. Clays Clay Miner. 1988, 36, 403-408. [CrossRef]

87. Konstantinou, I.K.; Albanis, T.A.; Petrakis, D.E.; Pomonis, P.J. Removal of herbicides from aqueous solutions by adsorption on Alpillared clays, Fe-Al pillared clays and mesoporous alumina aluminum phosphates. Water Res. 2000, 34, 3123-3136. [CrossRef]

88. Roca Jalil, M.E.; Baschini, M.; Rodríguez-Castellón, E.; Infantes-Molina, A.; Sapag, K. Effect of the Al/clay ratio on the thiabendazol removal by aluminum pillared clays. Appl. Clay Sci. 2014, 87, 245-253. [CrossRef]

89. Cardona, Y.; Korili, S.A.; Gil, A. A nonconventional aluminum source in the production of alumina-pillared clays for the removal of organic pollutants by adsorption. Chem. Eng. J. 2021, 425, 130708. [CrossRef]

90. Zhu, H.Y.; Li, J.Y.; Zhao, J.C.; Churchman, G.J. Photocatalysts prepared from layered clays and titanium hydrate for degradation of organic pollutants in water. Appl. Clay Sci. 2005, 28, 79-88. [CrossRef]

91. Phuekphong, A.; Imwiset, K.; Ogawa, M. Designing nanoarchitecture for environmental remediation based on the clay minerals as building block. J. Hazard. Mater. 2020, 399, 122888. [CrossRef] [PubMed]

92. Farghali, R.A.; Basiony, M.S.; Gaber, S.E.; Ibrahim, H.; Elshehy, E.A. Adsorption of organochlorine pesticides on modified porous Al30/bentonite: Kinetic and thermodynamic studies. Arab. J. Chem. 2020, 13, 6730-6740. [CrossRef] 